NBER WORKING PAPER SERIES

\title{
THE GENDER GAP IN TECH \& COMPETITIVE WORK ENVIRONMENTS? FIELD EXPERIMENTAL EVIDENCE FROM AN INTERNET-OF-THINGS PRODUCT DEVELOPMENT PLATFORM
}

\author{
Kevin Boudreau \\ Nilam Kaushik \\ Working Paper 27154 \\ http://www.nber.org/papers/w27154 \\ NATIONAL BUREAU OF ECONOMIC RESEARCH \\ 1050 Massachusetts Avenue \\ Cambridge, MA 02138 \\ May 2020
}

For support in operationalizing the research program described here, we wish to especially thank members of supporting organizations and particularly Maria Costa De Sousa, Hugh Courtney, Mavez Dabas, Sylvain Demortier, Anthony Donaldson, Raj Echambadi, Koreen Geisler-Wagner, Austen Keene, Afan Khan, Atif Khan, Abhinav Kharbanda, Dyan Khor, Raghavi Kirouchenaradjou, Sreerag Sreenath Mandakathil, Patrick McGrath, Tucker Marion, Marc Meyer, Robert Hughes, Michael Orr, Olga Ozhereleva, Kaushik Padmanabhan, Edwige Poinssot, Fernando Suarez, Prathamesh Kisan Tajane, Nikin Tharan, Emery Trahan, Maureen Underhill, Robert Whelan, and Katherine Wilhoit. For useful comments that influenced this article in important ways, we thank Victor Bennet, Roberto Fernandez, Sharique Hasan, Olga Shurchkov, and seminar participants at Duke University, DRUID, NBER productivity lunch, Northeastern University, and the Academy of Management. We would also like to acknowledge generous financial support from the Kauffman Foundation and Northeastern DMSB. The views expressed here are those of the authors alone and do not necessarily reflect those of the institutions, funders or supporters involved with this study. All errors are our own. The views expressed herein are those of the authors and do not necessarily reflect the views of the National Bureau of Economic Research.

NBER working papers are circulated for discussion and comment purposes. They have not been peer-reviewed or been subject to the review by the NBER Board of Directors that accompanies official NBER publications.

(C) 2020 by Kevin Boudreau and Nilam Kaushik. All rights reserved. Short sections of text, not to exceed two paragraphs, may be quoted without explicit permission provided that full credit, including $\odot$ notice, is given to the source. 
The Gender Gap in Tech \& Competitive Work Environments? Field Experimental Evidence from an Internet-of-Things Product Development Platform

Kevin Boudreau and Nilam Kaushik

NBER Working Paper No. 27154

May 2020

JEL No. C9,D2,J16,J2,J71,O3

\begin{abstract}
Many technology companies struggle to fill all their positions and to achieve gender parity in their ranks. One explanation for gender disparities is the possibility that men and women differ in their willingness to work under competitive organizational environments of tech firms. To investigate this question, this paper reports on a large platform-based field experiment in which 97,696 U.S. university-educated individuals were given the opportunity to join a tech-related product development activity. Individuals were randomly assigned to treatments emphasizing either competitive or collaborative interactions with other participants. We find that (1) in nonSTEM fields, the competition treatment leads to a $27 \%$ drop in participation for females in comparison to males. However, in our main finding, (2) in STEM fields, we find no statistical differences in men and women's responses to competition. The patterns are consistent with (3) men in non-STEM fields exhibiting overconfidence in their likelihood of succeeding under competition. We also find that, while participation in highest in STEM fields,(4) the ratio of female to male participation in a field is better predicted by whether the field is male-or femaledominated, than it is by whether it is a STEM field or not. We discuss theoretical interpretations and implications for organizations.
\end{abstract}

\author{
Kevin Boudreau \\ D'Amore-McKim School of Business \\ Northeastern University \\ 360 Huntington Avenue \\ Boston, MA 02115 \\ and NBER \\ k.boudreau@northeastern.edu \\ Nilam Kaushik \\ Bannerghatta Road, Bengaluru, India \\ IIMB \\ India \\ nilam.kaushik@iimb.ac.in
}




\section{Introduction}

Across US universities, women make up only about one in five of Computer Science and Engineering enrollees (NSCRC, 2017). Women's share of the tech labor force is even smaller, as women's attrition from year to year exceeds that of men, during and after university training (Silbey, 2016a). In fact, gender sorting and separation begins earlier in life, in early years through middle and high school in math and science subjects, before emerging in choice of university majors and workforce outcomes (Glass et al., 2013; Kahn \& Ginther, 2017). A large and vibrant literature on gender disparities provides a long list of possible explanations for gender gaps across the economy, in general (e.g., Bertrand \& Hallock, 2001; Blevins et al., 2019; Castilla, 2015; Fernandez-Mateo \& Kaplan, 2018; Guzman \& Kacperczyk, 2019; Scott \& Shu, 2017; Sherf et al., 2017). To date, there has been considerably less scholarly attention-and particularly systematic empirical research — devoted to gender gaps in the tech sector ${ }^{1}$ - this, despite the economic importance of this sector and conspicuous coverage of gender and tech in the popular media (e.g., Chang, 2018). (For exceptions, see: Fernandez \& Campero, 2017; Lambrecht \& Tucker, 2018; MurcianoGoroff, 2018; Wynn \& Correll, 2017.) Gaining more empirically-grounded understanding of explanations for the gender gap in tech might point to effective interventions - and perhaps then also means of moderating the "leaky pipeline" of native-born technical workers (US BLS, 2017). Gender diversity has also been shown to be correlated with group problem-solving and innovation performance in several contexts (Ancona \& Caldwell, 1992; Bear \& Woolley, 2011; Herring, 2009; Jang, 2017; Kneeland et al., 2020; Nielsen et al., 2018; Zhang, 2020).

This paper studies whether the tech gender gap can be explained, to any degree, by the notoriously competitive organizational environments in the tech industry, and associated gender differences in willingness to work in such environments. The tech industry is notorious for its highly competitive work

\footnotetext{
${ }^{1}$ The question of gender within sciences has received considerably more systematic empirical study (Ceci et al., 2014; Nosek et al., 2009).
} 
culture and incentives. For example, a report by Accenture that describes work environments of Silicon Valley firms noted, "employees are ambitious and will work harder and longer to do what it takes to get ahead, even if that means sometimes stepping on colleagues' toes" (Harris \& Alter, 2016). The New York Times, in describing the culture at flagship tech firm Uber, observed, "the focus on pushing for the best result has also fueled what current and former Uber employees describe as a Hobbesian environment at the company, in which workers are sometimes pitted against one another" (Isaac, 2017). Text analysis of 25,000 job postings by analytics firm Textio revealed striking patterns in the descriptions of many tech firms, suggesting competitively oriented organizational environments. For example, the top-three most common words used in Microsoft's postings (relative to words used outside of tech) were "driven person," “insatiably," and "competing" (Snyder, 2017). ${ }^{2}$ Analogous words connoting aggressive competition were found at many other tech leaders. Of course, the tech industry is also well-known for aggressive industrial competition, too.

In principle, any number of characteristics of tech organizations might shape men's and women's willingness to join (Evetts, 1996; Mcllwee \& Robinson, 1992). We are motivated here to study the role of competitiveness as one potential source of the gender gap, as there is a growing body of largely lab experimental research suggesting systematic differences in male and female responses to competition (e.g., Comeig et al., 2016; Gneezy et al., 2003, 2003; Iriberri \& Rey-Biel, 2019; Morin, 2015, 2015; Niederle \& Vesterlund, 2007; Paserman, 2010; Reuben et al., 2015; Shurchkov, 2012; Sutter \& Glätzle-Rützler, 2015). A tentative emerging consensus is that women could be more averse to working under competitive conditions than are men (Croson \& Gneezy, 2009). A misalignment of women's attitudes with the organizational environment might then dissuade entry to tech-related fields and perhaps also contribute to gender differences in attrition (Wynn \& Correll, 2017). If this were the case, we might ask, for example, whether redesign of organizational environments could moderate the gender gap (Slack Website, 2019).

\footnotetext{
${ }^{2}$ Exceptions included Slack, whose top words were "lasting relationships," "meaningfully," and "care deeply."
} 
At the same time, it remains a question whether the existing findings can necessarily be extrapolated to explain the gender gap under a quite different set of circumstances in tech. Although the existing findings on gender differences in response to competition have been replicated across multiple studies, these results are drawn from lab studies, largely with student subjects, and yet only a small number of field contexts, unrelated to tech fields. Also raising questions about the ability to extrapolate past results to the gender gap in tech, a set of rich descriptive studies of gender interactions in technical fields provides strong suggestion that gender differences in attitudes to competition (and collaboration) could be more nuanced and ambivalent in male-dominated technical fields than they are in other contexts (e.g, Friesel \& Timcenko, 2011; Kuyath \& Yoder, 2004; Silbey, 2016). Further, others studying the antecedents of attitudes to competition, such as self-confidence, have found that men and women in technical fields could be more similar to one another in these respects than those in non-technical fields (Beyer \& Haller, 2006; Nekby et al., 2008). Therefore, it is an empirical question whether gender differences in attitudes to competition generalize to tech contexts. And, we it is the case that these differences generalize, it is still a question whether any such differences are of a magnitude to explain a significant share of the staggering one-in-five gender gap in tech.

To make progress on these questions, we report on a field experiment covering 97,696 alumni and students from a large private R1 American university with top-40 ranked undergraduate programs in Business, Computer Science, and Engineering. Study subjects are from all fields and career stages (from youngest undergraduates to post-retirement). We focus on the decision of these individuals to participate in a tech-related product development activity (or not). The program involves a 3-week part-time commitment in one's off-hours, engaging in tech-related product development. The work involves conceiving and designing applications related to the Internet of Things (IoT), a current leading area of development and innovation in the tech industry. Prospective participants were randomly assigned to treatments designed to generate expectations of either competitive or collaborative interactions among platform participants. The experiment was embedded within the initial launch campaign and takeoff of the platform and prior to initial operation. 
The research design here builds on past experimental methods (e.g., Flory et al., 2015; Niederle \& Vesterlund, 2007), but introduces refinements to the experimental protocol and targeted study population that allow a larger and wider group of heterogeneous subjects to be studied. The ability to discern differences across subjects in technical and non-technical fields is especially important here, given the experiment is preceded by lifelong sorting of subjects into technical and non-technical fields (i.e., we should interpret results as reflecting "sorting-of-the-already-sorted".)

When replicating the essential approach of past studies - comparing pooled average responses by men and women - we are able to replicate past results. We find that average female participation is $25 \%$ lower in the Competition Treatment; and 20\% lower for mean, consistent with the past research. The general preference for collaboration is also consistent with past research (Dargnies, 2012). However, these results are fragile when considering within sample heterogeneity; simply controlling for field fixed effects eradicates this finding. (Participation is highest in Computer Science, Engineering and Sciences.)

Our main results and contribution relate to comparisons between comparable men and women in the same field. We find that the prevailing wisdom - that women are more averse to competition — is true in non-STEM fields, where women reduce participation by $27 \%$ in response to the Competition treatment, whereas men are statistically indifferent to Competition. Given that men in non-STEM fields might be understood to be disadvantaged developing products in the Internet of Things than those with technical backgrounds, this indifference by men in non-STEM fields is consistent with over-confidence (cf. Niederle \& Vesterlund, 2007), if we interpret those in non-STEM fields as being disadvantaged in competition by a lack of relevant technical knowledge. By contrast, men and women in STEM fields have statistically indistinguishable responses to the Competition treatment, reducing participation rates by $21 \%$ and $19 \%$. We find that the similarity of men's and women's responses to competition in STEM fields is consistent with prior findings in the literature of more similar levels of self-confidence and self-efficacy among men and women in technical fields (e.g., Beyer \& Haller, 2006; Nekby et al., 2008).

Estimates are robust to controlling for available measures of individuals' academic achievement, opportunity costs, age and cohort, or whether the field was male- or female-dominated. (General 
participation rates were lower with age, lower among those in primary child-rearing years, and lower among females with high GPAs. We also find that the relative participation rates of females to males are especially well predicted by whether the field was male- or female-dominated. As we later discuss, these associations are potentially indicative of gender socialization within fields. Most important to our main research questions, we find these relationships are unrelated to effects of the Competition treatment.

And so, could gender differences in attitudes to competitive organizational environments explain the gender gap in tech? Prima facie, it is far from clear. The gender differences in responses to competition observed here are small relative to the staggering one-in-five gender gap; moreover, the differences that do appear do not even relate to those in technical STEM fields. However, we discuss organizational and policy implications when interpreting results as reflecting the lifelong gender sorting and separation to distinct fields that occurs prior to the sorting that occurs within the experiment, itself.

This study draws together and contributes to three literatures. First, it contributes to the vast literature on gender disparities in organizations general (e.g., Bertrand \& Hallock, 2001; Blevins et al., 2019; Castilla, 2015; Fernandez-Mateo \& Kaplan, 2018; Guzman \& Kacperczyk, 2019; Scott \& Shu, 2017; Sherf et al., 2017). In this case, we isolate the effects of a particular behavioral mechanism on the gender gap - gender differences in attitudes to competition. Here, we add to the small but growing number of papers providing systematic empirical evidence on gender in tech. We also contribute to research on gender differences in attitudes to competition (e.g., Comeig et al., 2016; Gneezy et al., 2003, 2003; Iriberri \& ReyBiel, 2019; Morin, 2015, 2015; Niederle \& Vesterlund, 2007; Paserman, 2010; Reuben et al., 2015; Shurchkov, 2012; Sutter \& Glätzle-Rützler, 2015). Relative to this literature, we illustrate-with a large and wide study population — that gender differences in responses to competition can vary by field, providing a contrasting example counter to usual findings in this literature. The focus on field experiments, and particularly at scale, remains rare in this literature (see Flory et al. (2015) for a notable exception). In this regard, this study is distinct for its especially larger scale, while systematically observing heterogeneous participants. We also drew upon rich descriptive studies that characterize gender interactions in technical fields collaboration (Friesel \& Timcenko, 2011; Kuyath \& Yoder, 2004; Silbey, 2016). We contribute to 
this literature with large-scale empirical evidence that is less rich and nuanced but provides causal evidence to add to and complement our understanding of these complex behavioral environments.

\section{Gender-Based Sorting \& Competitive Organizational Environments}

\subsection{Evidence on Gender Differences in Responses to Competition}

A growing body of largely lab experimental research finds, in many cases, that a greater proportion of male subjects exhibit a willingness to work under competitive conditions than do female subjects. The typical experiment follows this template: a group of participants are recruited to the experiment and introduced to a task such as solving puzzles, completing math problems, etc. and are asked to choose between a (non-competitive) piece rate payment scheme or a (competitive) tournament incentive schemethus distilling the nature of a competitive work environment down to how payoffs are allocated.

For example, Niederle and Vesterlund's lab experimental study of 80 students from the University of Pittsburgh has become a key reference and referent experimental protocol in this literature. The group of half men and half women who performed arithmetic (Niederle \& Vesterlund, 2007) calculation for five minutes and could choose to work under the competitive or non-competitive payoff scheme. Subjects could be paid $\$ 1$ for the piece-rate regime, or could alternatively choose to compete with another person could and be paid $\$ 3$ for winning (along with payments for participating in the experiment). Men chose the competitive regime twice as often as the women ( 73 percent versus 35 percent), with low-skilled men entering the competitive tournament too often, and high-skilled women not entering as much. Men's performance also increased under competition. ${ }^{3}$ The main results have been replicated across a range of study groups, tasks, and variants on the original protocol (e.g., Comeig et al., 2016; Gneezy et al., 2003; Iriberri \& Rey-Biel, 2019; Morin, 2015, 2015; Paserman, 2010; Reuben et al., 2015; Shurchkov, 2012;

${ }^{3}$ Of course, it is not possible to unambiguously estimate a causal "gender effect"- - even when one compares men and women in a randomized controlled experiment. The sex of individuals in any research study group is likely to be correlated with any number of omitted variables; neither random assignment nor deliberate sampling strategies allows the coefficient on a gender dummy to be interpreted as a "gender effect" (Holland, 1986). Nonetheless, in Niederle and Vesterlund's study, the result gains credence by showing men and women performance similarly, on average, in the task prior to the experiment. 
Sutter \& Glätzle-Rützler, 2015). (Closely-related studies find instances where women are also shown to have a preference for collaboration (e.g., Kuhn \& Villeval, 2015).)

These findings of residual differences between male and female subjects have been described as gender differences in "attitudes" towards or "preferences" for competition within this research stream, with some suggestion these differences could be based on biological or evolutionary factors (Buser, 2009; Croson \& Gneezy, 2009; Knight, 2002; Lippa, 1998), gender differences in confidence and self-efficacy (Comeig et al., 2016; Niederle \& Vesterlund, 2007), and socialization of beliefs and stereotypes around gender-role incongruity (e.g., Günther et al., 2010). ${ }^{4}$

\subsection{Competition and Gender Sorting}

Several recent papers have built on the main results of this literature and asked whether gender differences in attitudes to competition leads to sorting in education and employment contexts. For example, Reuben et al. (2015) assess MBA students' attitudes to competition and find that, in the following decade, gender differences in taste for competition correlate with wages and likelihood of working in high-paying industries. Saccardo et. Al (2018) estimate the magnitude of the gender gap in competitiveness in a lab experiment and find that the top $10 \%$ of the competitiveness distribution is comprised of men. Their results suggest that although women may choose to select into moderately competitive environments, they may opt out of highly competitive ones. We may, therefore, expect fewer women to commit to career paths in segments of the labor market that are highly competitive in nature.

Perhaps closest to the methodology of the current study, work by Flory et al., 2015 is notable for documenting a first large-scale field experiment that tests whether competitive incentives advertised in Internet job postings for administrative assistant jobs leads to gender-sorting among 6,779 job seekers. In the main arm of their experiment, the authors randomly varied compensation schemes advertisedincluding competitive or team-based compensation schemes - across jobs and cities. The authors find that

${ }^{4}$ Gender differences in experiments have also been reported in relation to factors that are coincident with competition, such as risk-taking, preferences for high-powered incentives, psychological "choking," and subjective beliefs concerning the implications of competition (Croson \& Gneezy, 2009). 
women in cities with higher prevailing local wages were less likely to apply to competitively oriented job postings than were women in cities with lower local wages. They interpret the pattern as suggesting that women will tend to avoid the competitively oriented job postings if there are other local opportunities.

Perhaps closer to our focus here on the tech industry than administrative assistant jobs, is research finding associations between competitive environments and gender differences in sorting and performance in mathematical training, among young people (e.g., Buser et al., 2017; Jurajda \& Münich, 2011; Ors et al., 2013).

\subsection{Competitive Organizational Environments \& the Tech Gender Gap?}

Given the notoriously competitive organizational environments in tech (see Introduction), the above findings suggest that gender differences willingness to work under competitive conditions might at least partly explain the gender gap in tech, adding to a number of explanations. If this were the case, it would still be an empirical question whether this factor accounts for much of the staggering one-in-five gender gap (see Introduction). However, as outlined below, it is even a question whether past findings can be extrapolated to explain the gender gap, at all.

\section{Possible Limits to Extrapolating Prior Studies}

In view of the considerable degree of replication of results and even an emerging tentative consensus that women are more averse to competition than are men, there are a considerable number of studies suggesting exceptions to this rule. These exceptional studies and their interpretations suggest that gender differences in responses to competition could depend on the nature of the task (Dreber et al., 2011; Günther et al., 2010; Shurchkov, 2012), familiarity with a domain of knowledge (Wieland \& Sarin, 2012), the gender composition of the competing group (Gneezy et al. 2003; Gneezy and Rustichini, 2004; Antonovics et al., 2009), the background and culture of the study group (Andersen et al., 2013, 2013; Booth et al., 2019), socialized perceptions of gender-role congruity (Günther et al., 2010) and age (Flory et al., 2018). Further, Apicella et al. (2017) find that gender differences disappear when competing with oneself, rather than competing with others. Dargnies (2012) reports of men and women preferring to collaborate 
with others rather than entirely competing on their own, before entering into a set of steps following the Niederle-Vesterlund protocol. Therefore, even the existing largely lab experimental research, distant as it may be to tech industry contexts, already raises questions concerning boundary conditions and limits the applicability of main consensus findings.

\section{Ambivalence to Competition and Collaboration in Tech Fields}

Outside of what is known from the literature on gender differences in responses to competition, there are also important insights that can be drawn from the research describing the role that gender plays in interactions in tech fields. One possible source suggested by the literature of gender differences in responses to competition (and collaboration) in STEM fields relates to more complex or ambivalent responses in a highly gender-socialized contexts. For example, rich case study evidence indicates that female engineers are often not so much averse to competition, as they are averse to teams and collaboration. This is because teamwork can subject females to gender-stereotyped expectations and work role assignments or other forms of bias, when working with male counterparts (Cech et al., 2011; Cheryan et al., 2017; Choi, 2013; Foor et al., 2013; Mcllwee \& Robinson, 1992; Moss-Racusin et al., 2018; Silbey, 2015, 2016b). Other observers describing women in technical fields, as Engineering, in fact point to Engineering competitions as a means of further engaging and socializing women and girls into the field, rather than dissuading them (Friesel \& Timcenko, 2011; Kuyath \& Yoder, 2004; Notter, 2010). The interaction between competition or collaboration and gender are consistent with prior claims in the literature

that gender and peer effects could play an important moderating role (Gneezy et al. 2003; Gneezy and Rustichini, 2004; Antonovics et al., 2009).

\section{Behavioral Similarities of Men and Women in Technical Fields}

A second set of particulars in tech fields that raises still more questions relates to the behavioral orientations of men and women who pursue technical fields. As context, prior research finds that men's higher inclination towards competition can be related to over-confidence in expected performance (Niederle \& Vesterlund, 2011). By contrast, numerous past studies have suggested women may experience lower 
self-efficacy, or subjective perceptions of their own capacity (Correll, 2001, p.; Marra \& Bogue, 2006; Tang, 2019), which would then discourage them from competing with others. However, evidence on those in STEM fields suggests that women in technical fields have may be more similar to their male peers in terms of self-efficacy than they are to females in other fields (Beyer \& Haller, 2006). Moreover, despite the preponderance of evidence pointing to lower self-efficacy among women — and especially in mathematical activities (Ellis et al., 2016) — those women who choose to self-select into male-dominated fields may in fact diverge from this tendency, and in fact relatively over-confident (Nekby et al., 2008).

From these arguments and the qualifications of the existing results in literature on gender attitudes to competition, the relation between gender, competition, and willingness to participate is a complex question and we treat this as an empirical question.

\section{Research Context}

This research was carried out in collaboration with Northeastern University's IoT Open Innovation Lab. Northeastern University is a large R1 research-oriented University in the United States, based in Boston, founded in 1898. It has roughly 18,000 undergraduate students, 8,000 graduate students and more than two hundred thousand alumni. The university is ranked $40^{\text {th }}$ according to US News Reports' list of best US universities, featuring nationally ranked undergraduate programs in Engineering, Computer Science, and Business. The average high school admittance GPA at Northeastern is 4.04 with an admittance rate of $18 \%{ }^{6}$ The large majority of the school's alumni live in the United States, with largest clusters in Massachusetts, New York, and California.

\footnotetext{
${ }^{6}$ These facts were sourced from the following link https://www.prepscholar.com/sat/s/colleges/NortheasternUniversity-SAT-scores-GPA. Parenthetically, although the academic curriculum and range of fields offered is relatively typical of large private universities in the United States, the student population of this university is distinguished by the university's "cooperative" experiential education program. This implies that the vast majority of students alternate between 6-month academic terms to 6-month professional employment in industry positions within their field of study (with most students taking three 6-month work terms in their field before graduating). Thus, the study population here - students and alumni alike - will have industry experience working in their fields.
} 


\subsection{Background: The Internet of Things (IoT)}

The Internet of Things or "IoT" refers to a wide set of mostly yet-to-be-imagined products, services, and systems that connect machines, infrastructure, consumer products and other things, while making use of the intelligence created by data collection and networking. In another sense, IoT represents a recombination of existing information technologies, combined into a single technological "stack," including artificial intelligence, wireless networks, sensors, software, data science methods, control systems, "big data" and cloud-based computing, information security, robotics, and the like. Thus, IoT product and services are, in many ways, also directly representative of today's tech industry. It is therefore not surprising that differences in gender representation in tech have been reflected equally in this emerging sector. $^{7}$

IoT also has special economic relevance and applies to most every sector of the economy, just as in earlier generations of the Internet. The technologies making up the IoT technology "stack" represent a general purpose bundle of technological capabilities that are associated with visions of a "Fourth Industrial Revolution" (Schwab, 2017) or a "Second Machine Age" (Brynjolfsson \& Mcafee, 2014; McAfee \& Brynjolfsson, 2018). For example, many of the prevalent technological changes in these thesesautomation, artificial intelligence, and robotics - are subsets of the IoT technical stack. Thus, IoT is expected to be applicable across the economy, as another example of a general purpose technology (Trajtenberg, 2019). Accordingly, management consultants McKinsey \& Company predict that IoT could grow to trillions of dollars in the next decade and as much as 10 percent of global economic output (Patel et al., 2017).

\subsection{IoT Product Development Program \& Platform}

We worked with Northeastern's IoT Open Innovation Lab, which runs a program that allows Northeastern's alumni and students to be assembled into teams and compete with one another in designing

7 See "Women of IoT say push diversity, don't patronize and don't discriminate" downloaded at https://www.iot-now.com/2018/10/09/89071-women-iot-say-push-diversity-dont-patronise-dont-discriminate/ 
new tech products related to IoT. The entire program is structured and run on an online product development platform.

The program's goals are to provide participants with opportunities to design IoT product (“applications”), while gaining understanding of IoT building-block technologies, how they fit together and overall architecture of IoT systems. These goals are accomplished through a series of part-time learningby-doing product development activities to be pursued in off-hours, organized as team-based "challenges," designed as team-based rank-order tournaments. To facilitate system design, participants were to engage with a drag-and-drop tool to design the technical architecture and visually convey the key workings of their designs, while also working through a structured series of questions to convey key workings of their designs.

A key tenet of the program's design was to create technical challenges and learning opportunities for users from a wide variety of backgrounds. For example, those with highly advanced knowledge in related tech areas could provide rich technical detail with their designs, well above the bare minimum requirements for completing a submission. Further, pre-testing of the platform with advanced users confirmed that the technology stack in IoT was considerably broader than their areas of experience. For those with little knowledge of IoT and key technology concepts, the platform was designed to create clear steps and baseline concepts to allow them to understand how technologies fit together and what process steps they should follow to successfully learn about the technologies and to subsequently create a design concept. The minimum level of design consists of a high-level architecture design and some description of data flow and functionality. In these ways, the platform user experience was designed with a philosophy and approach of "low floors and high ceilings" (Boaler, 2016) to meaningfully engage the widest possible range of possible participants - with all participants finding the challenge accessible and also meaningful and, indeed, challenging. ${ }^{8}$ Step-by-step instructions and scope for developing either highly detailed or quite

${ }^{8}$ We pretested the platform, itself, on 30 individual students drawn from all fields across the university and several administrative staff. We also pretested the platform with teams formed from 79 graduate business students. Participants uniformly reported awareness that this was to be a tech-related tasks. It was relevant, in the majority of 
basic designs created additional scope for low floors and high ceilings of challenge, difficulty, and ambition. The digital nature of the platform and ability to carry out the work either synchronously or asynchronously, to communicate and to collaborate on the platform also enhanced accessibility. The program and platform were designed to allow online interactions and guided work steps; however, collocated individuals could certainly also work side-by-side and in person. Apart from technical aspects, designs created on the platform also require a description of target users, needs and use cases, and basic analysis of costs and benefits of advancing to build a prototype.

Participants are not charged to participate but bear the opportunity cost of time in participating, in hours outside or school or work or other responsibilities. Participants benefit from engaging in interesting projects, from learning, from enjoying interacting and networking with other university community members, from getting feedback on designs, and from cash prizes for individuals in top-ranked design teams. Several teams have benefitted too from taking their conceptions and designs and feedback through to follow-on entrepreneurial development off the platform.

There are now over 5,500 participants on the platform, with participants distributed across all fields of training and career stages. Participants reside in 50 U.S. states, and countries throughout the Americas, Europe, Australia, and Asia, and several African nations. Participants span all fields of study, include a wide range of students, professionals, entrepreneurs, retirees, investors, military veterans, businesspeople, unemployed and under-employed, educators and teachers, technical experts and engineers and computer science graduates, unemployed or under-employed workers, Ph.D. researchers, and the physically handicapped. ${ }^{9}$

cases, to explicitly state that the product development steps would be designed in a way to allow them to successfully proceed and complete the tasks, although those with more technical background should be able to provide more detailed technical responses. In those pretests, the individuals also proceed to in fact complete the steps, confirming a large variation in depth and detail in designs produced.

${ }^{9}$ The program was designed for people do engage on the platform and, by its design, allow people to engage through learning-by-doing in a structured environment, where interactions and collaborations could take place wholly online, whether synchronously or asynchronously. It was still possible for people to meet in-person, in cases where they were collated, and still work over the platform. 


\section{$4 \quad$ Field Experimental Research Design}

To explore the question of whether men and women respond differently to the expectation of a competitive organizational environment when choosing to pursue a tech-related opportunity or not, we carry out a large field experiment, described in this section.

\subsection{Timeline \& Random Assignment Procedure}

\section{Platform Launch Campaign}

We "embedded" the experiment in the initial launch campaign of the IoT Open Innovation lab platform described above. The goal of this initial growth campaign was to carry out a one-time intensive outreach to gain a "critical mass" of participants on the platform, as the value generated on the platform depends on interactions among participants. Embedding our experiment in this initial launch allowed us to be part of a one-time process of mass communicating with 97,696 potential adopters of the platform, given a known roster of alumni and students. (This number of 97,696 is the subset of all students and all alumni who were involved in mass communications, for which anonymized descriptive data were available for our analysis.) Embedding this experiment within the initial launch of the program allowed us to implement the research prior to individuals having prior experience with or knowledge of the platform.

\section{Assignment to Separate Email Outreach \& Sign-up Platforms}

The launch campaign involved contacting students and alumni for whom contact details were available (and in the case of alumni, those who had opted into university communications). An introductory email served to introduce the opportunity and invited the individual to click through to the program platform to learn more details and to join (see Appendix). Subjects received emails at 10 am EST. Individuals were randomly assigned to be contacted over 67 business days. ${ }^{10}$ Individuals who did not act on the email were sent a single reminder seven days later (also at 10am EST). We explicitly added a line in the email stating

${ }^{10}$ Spreading invitations over time mitigated the risk of any one day providing eccentric results, while also allowing the engineering team to carefully monitor the performance of the platform in relation to scaling and growth. Staggered roll-out was also used to test an orthogonal treatment of informing potential adopters of the number of prior adoptions. This secondary intervention was orthogonal to this study and has no effect on the results reported here. 
that the invitation was not transferable or to be forwarded. Nonetheless, there were 26 instances of forwarding of emails; we were able to detect such forwarding and we removed these instances from our analyses. Opening rates for females and males were statistically identical, with 46.5 percent of females and 45.9 percent of males opening.

Individuals were randomly assigned to Competition or Collaboration treatments, designed to influence subjects' expectations regarding the nature of interactions with other participants while engaging in product development activities in the program. Both treatments consisted of mostly identical introductory emails and the ability to click through to a platform with further information and the ability to sign-up to participate (see Appendix). The all facets of the treatments were identical excepts for several narrowly specified differences. Within the introductory emails, Competition and Collaboration treatments were distinguished only by a subset of words (which were also bolded for emphasis in the reader's mind). Here is an excerpt from the email in the Competition treatment:

"This is a two-sided competitive platform to ideate and innovate "smart" Internet of Things (IoT) products and services - using hardware, software, networking, data and algorithms. On one side of the platform, companies seek solutions to their IoT innovation challenges. On the other side, you will compete with other participants to solve IoT innovation problems of companies for cash and other benefits."

In the case of the Collaboration treatment, the bolded words were replaced with "collaborative platform," and "you will work within a team to solve IoT innovation." Therefore, the content and length of letters were virtually identical, with differences bolded for emphasis. We were able to alternatively emphasize either competitive or collaborative descriptions, as they were both true: the program they would soon enter into involved competition among teams.

Clicking through from the email ("Click HERE to learn more and to sign up to the platform") sent the individual to an online sign-up platform page. The sign-up platforms for the Competition and Cooperative treatments were mostly identical in content, length, and structure. The platforms provided a brief high-level description of the technical nature of the Internet of Things, described the opportunity to create new products and applications, and offered a means of signing up (using LinkedIn credentials). the 
landing pages of the platforms also repeated (and continued to bold) the same key bolded messages from the emails, for reinforcement of the differences across treatments. The landing page of the platforms for each treatment also used similar color schemes and design motifs, however, that in the Competition treatment further emphasized competition by showing stylized figures of people running in a race (see Appendix). ${ }^{11}$ The platform provides more basic background on the Internet of Things and also steps to signing-up.

\section{Randomization Procedure}

Randomization was carried out in a way as to block randomize individuals by field, with equal numbers of men and women being randomly assigned by treatment. These groups were then distributed randomly across the 67-day outreach campaign in a way that the distribution of fields and of gender across any one day was held to the population average.

\section{Signing-up of Participate}

We emphasize again that this priming of subjects took place before the initial launch and operation of the platform; the messaging and information provided here were meant to deliberately influence expectations of what they will encounter. The emphasis was to ensure they understood the essential technical definition of the Internet of Things (as being made up of a wide range of information technologies), of the sort of product development opportunities that could exist, that this program and platform would be designed to admit people from all fields, and was being made available only to alumni and students in the university community, and would be in the interest of exposing community members to new technologies. Further, the intent in the Competitive and Collaboration treatments was to influence expectations by quite literally using the words "competition" and "collaboration," rather than imposing any

${ }^{11}$ We repeated key messages of the introductory emails on the landing pages with the interest of reinforcing expectations and the strength of the experimental priming. Consistent with this intent, the analysis provides similar results whether analyzing the choice to join participate conditional on going to the landing page or analyzing the decision to go to the sign-up platform after seeing the note. The former, reported here, provides more statistically significant results, again consistent with the stronger effect. 
particular interpretation or definition on those words. It was also emphasized that this would require a commitment of 3-weeks during off-hours. Mention was made too of "prizes and benefits," in general.

Based on that level of priming, subject on the platform could elect to participate. This was done by clicking on a red "join and participate" button prominently displayed on the site. Users were prompted to sign-in with their LinkedIn password. This sign-in and authentication takes place through an API with the LinkedIn site, and users were prompted that their LinkedIn picture, name, link and brief blurb would be used to create their platform profiles.

\section{Experimental Protocol Relative to the Prior Literature}

The framework here is similar to, but slightly differs from some of the experimental protocols described in Section 2, in which subjects select into a task (the lab experiment) and then choose a competitive or alternative regime within the experiment. Here, instead, we focus on the decision to participate, conditional on individuals being randomly assigned to the Competition or Collaboration organizational environment—without having to explicitly self-select into the experiment. Our study population is therefore able to be a wide risk set of potential participants. In this sense, the approach is closer to that of Flory et al. (2015), which focuses on a participation decision of a kind, or at least a decision to apply (where they focus on a pre-existing population of job seekers of administrative assistant employment). Also worth noting, we refer to "competitive" and "collaborative" work environments, allowing subjects to conceived of whatever images they have of these things, rather than focusing only on the schedule by which payoffs are bestowed. This may allow us to better bridge the multiple literatures we draw on here.

\subsection{Study Population \& Randomization Checks}

In this initial launch of the platform, our sample covers 97,696 people: 7,584 currently enrolled students and 90,112 alumni. (The total number of individuals invited to join in the initial campaign was 110,492; however, it is only for these 97,696 for which we have data on individual characteristics.) We do not have data on their location, but the distribution of the university's alumni is known by university 
officials to be concentrated in the United States, with largest clusters in Massachusetts, California, and New York. This population or "risk set" of potential participants covers all fields and individuals from earliest years of university through to retirement. Table 1 describes main variables that will be used in the analysis. Table 2 summarizes the distribution of individuals and gender breakdowns by field and by cohort.

$<$ Table 1>

$<$ Table 2>

Further, while randomization should ex-ante lead to equal groups in treatment and control, Table 3 tests and confirms that balance of groups was achieved ex post.

$<$ Table 3>

\section{$5 \quad$ Results}

This section presents the results of the experiment. In the first subsection, we report the baseline mean gender differences and treatment effects. In the next two subsections, we report the mean gender differences across fields and within fields. In the last subsection, we attempt to rule out alternative explanations.

\subsection{Baseline Mean Gender Differences and Treatment Effects}

Table 4 presents estimates of population-average differences between men and women in rates of participation and how these rates change under the Competition treatment. The main purpose of this section is to replicate usual practice of presenting average gender differences, revealing results consistent with past literature on gender differences in attitudes to competition (Section 2.1). A linear probability model is estimated by OLS with heteroskedasticity-robust standard errors reported. ${ }^{12}$

Model (1) summarizes overall gender differences in participation across the experimental population, regressing the decision to participate or not on a female indicator variable and a constant.

\footnotetext{
${ }^{12}$ A linear model will ease interpretation of a number of interaction terms that are central to the investigation.
} 
Coefficients are expressed as percentage points (i.e., $100=100$ percent). The constant term, or probability of males participating, is $3.19 \%$ (s.e. $=0.08 \%$ ), with the coefficient on females being negative $0.67 \%$ (s.e.= $0.11 \%$ ). These estimates imply that females are $21 \%$ less likely to participate than men, overall. (The low adjusted- $R^{\wedge} 2$ statistic is consistent with a high variance in cases of a binary outcome variable with a low mean incidence of 1's.) These differences in willingness-to-participate between men and women exist over different ages, those with different grade point averages, and over students and graduates, as shown in Figure 1.

$<$ Figure 1 $>$

Model (2) estimates the effect of being in the competitive treatment versus the collaborative treatment, introducing the treatment dummy into the model. Those assigned to the competitive treatment are, on average, 0.71 percentage point less likely to participate.

To measure any differences in men and women's responses to competition, model (3) introduces an interaction term between the treatment effect and gender. This interaction term is found to be statistically zero. Note, however, a zero-interaction term still implies a greater proportional response of women to the Competition treatment. A similar absolute diminution in participation relative to a lower baseline participation level implies a greater proportional effect of competition among women. Women reduce their participation by $25 \%$ under competition; whereas men reduce their participation by $20 \%$ under competition.

The results are unaffected by controlling for the particular day in which the individual received the invitation to join over the 67-day campaign (model 4), controlling for students versus alumni (model 5), or controlling for individual fixed effects for year of graduation (model 6). The more negative effect for women is consistent with past findings on gender differences in attitudes to competition (Section 2.1). The absolute preference of both men and women for working with others in teams is consistent with prior work by Dargnies (2012).

$<$ Table 4>

As part of this baseline analysis, we also wish to assess whether the patterns we are measuring relate particularly to this IoT product development activity, or whether they simply might reflect a 
willingness to participate in extracurricular activities, more generally. To do so, model (8) replaces the dependent variable with a count of the number of clubs and extracurricular activities listed on LinkedIn for students. (Model (7) simply begins by showing that re-estimating the earlier model on just the data for which we have extracurricular activity data does not affect results.) We are able to match data for 8,460 students in our data. As reported in model (8), we see starkly different patterns. Whereas women are, on average, less willing to participate in this IoT product development in comparison to men, the coefficient on Female for club participation is positive, indicating the very opposite. (Of course, coefficients on the treatment is statistically zero for this model.)

\subsection{Differences Across Fields}

As we study willingness to participate in (i.e., sort into) this tech product development activity, inevitably we are studying a population that has already sorted into technical and non-technical fields. Table 5 reports the implications of controlling for these cross-field differences. This section principally shows the earlier results are annihilated by simply controlling for field fixed effects.

Models (1) and (3) re-report the population-average results, as comparison. Models (2) and (4) reestimate those models with field fixed effects. The coefficients on the field fixed effects (ordered by magnitude) indicate that those in STEM fields of Computer Science, Engineering, and Science participate more than those in other fields, as would be expected given the nature of the activity. However, accounting for field differences does not entirely account for the gender difference. The coefficient on Female in models (2) and (4) is not zero and, in fact, becomes positive.

Therefore, on the one hand, the results clearly indicate controlling for fields (accounting for differences in how men and women tend to sort to different fields) has a first-order effect in accounting for population-average gender differences in the experiment. On the other hand, the flipping of sign is consistent with important within-field differences that deserve closer examination.

$<$ Table 5> 


\subsection{Main Results: Differences Within Fields}

This section more closely examines within-field differences between STEM and non-STEM fields. The main finding here is that when more closely comparing comparable men and women in the same field, we find the usual finding of women being more averse to competition than men, but only in non-STEM fields. In STEM fields, there are not statistical differences between men and women's responses to competition. Results of this section are reported in Table 5.

Model (1) first re-reports the earlier overall gender differences and responses to treatment, controlling for fields. Models (2), (3), and (4) introduce an indicator for Engineering, Computer Science, or Sciences — those fields with highest participation — which we refer to as the STEM indicator. ${ }^{13}$ Model (2) through (4) progressively introduce interactions between STEM, Female, and Competition. (STEM, itself, is redundant to the field fixed effects.) Models (2), (3), and (4) reveal a large significant coefficient on STEM Field $\times$ Female, roughly one percentage point. This indicates that the difference in participation between males and females in STEM is much larger than the difference in participation between males and females in non-STEM fields. ${ }^{14}$

$<$ Table 5>

While the point estimate of the coefficient on Competition remains negative across models (2), (3), and (4), the most flexible specification in model (4) leads the coefficient on the interaction Female $\times$ Competition to become more negative and statistically significant (at $p=5 \%$ ). This gender differences in the treatment effect is only significant in the case of women in non-STEM fields.

Given the great many interactions to interpret in model (4), we more explicitly report results stratified by non-STEM and STEM fields in models (5) and (6). This most explicit reporting shows the coefficient on Female $\times$ Competition is -0.47 percentage points and significant at $p=5 \%$, in the case of non-

${ }^{13}$ We did not include Health Sciences and Nursing in this STEM indicator on the basis of the clear overall participation differences with Computer Science, Engineering and Sciences.

${ }^{14}$ The interaction between STEM Field $\times$ Competition is also significant and negative. However, we interpret this as effectively just a scaling of the generally negative competition effect in the case of STEM, as overall participation and overall effects are each larger in STEM. 
STEM subjects in model (5). This is a large difference between men and women's response to competition, considering that overall participation rate by non-STEM women is 1.98 percent. By comparison, in STEM fields, the interaction term between Female $\times$ Competition is not statistically different from zero. The response of males to competition in non-STEM fields is statistically not statistically distinguishable from zero, despite the extraordinarily large sample size here. (If we were to regard the small point estimate of the coefficient on Competition to be meaningful, even then women's negative response to competition is a full 5.3 times greater, i.e., $5.3=(-047-0.11) /(-0.11)$. $)$

Results in the STEM subsample are quite different, as in model 6), with men and women responding similarly to competition, as per the highly negative coefficient on Competition of -0.87 percentage points, significant at $p=1 \%$. In great contrast to the results in the non-STEM model (5), where the coefficient on Female $\times$ Competition was many times larger than the coefficient on Competition, in the STEM model (6) the coefficient on Female $\times$ Competition is statistically indistinguishable from zero, ${ }^{15}$ meaning the response of men and women is statistically undetectable even when comparing tens of thousands of observations. At the bottom of Table 5, we summarize by expressing the significant coefficient results in relation to average participation by men and women in STEM and non-STEM fields.

\subsection{Robustness}

The previous section presented the main findings of fact- that there are significant gender difference in responses to the Competition treatment in non-STEM fields, but not in STEM fields. Here we exploit the available data to examine robustness. Model (1) of 7 begins by re-reporting the earlier patterns found.

${ }^{15}$ In finding a null empirical result, it should always be a question of whether the estimate is simply underpowered. If the point estimate were indeed truly meaningful, this would imply that differences between men and women's responses to competition are sufficiently subtle that even tens of thousands of observations of STEM men and women are insufficient for detecting any meaningful difference in responses. 


\section{Individual Controls}

Model (2) considers the possibility the age and cohort distribution of men and women could somehow vary across fields in ways that account for differences in responses to competition, adding a linear cohort trend to the model. This has no effect on main results. (Results are similarly unaffected by controlling for either a quadratic time trend or distinct trends for either sex.)

Another determinant of participation is likely to be an Individuals' opportunity costs, where the relevant question is whether opportunity costs could somehow influence responses to competition. To test for such a possibility, include one particular measure of variation in opportunity costs, being on prime childrearing years from late twenties to mid-thirties (controlling for a more general age trend). Model (3) includes an indicator switched on for ages 29 through 35 (or rather an approximation of ages based on graduation year ${ }^{16}$ along with an interaction with gender. We find child-rearing years are associated with significantly lower participation, but main results remain unchanged. (Again, controlling for linear, quadratic, or gender interactions in cohort trends does not alter results.)

$<$ Table 7>

We next attempt to find evidence that variation in measures of the achievement of subjects could somehow explain our results. For example, women score slightly higher grades, on average, in STEM fields. We use undergraduate cumulative GPA as a proxy for such differences. We have these data for 13,926 individuals from cohorts graduating in 2009 or later. Model (4) begins by re-estimating the main model on this subsample, revealing similar patterns of signs on main coefficients. It is not surprising that coefficients are larger, given younger subjects are more likely to participate. Model (5) re-estimates the model while including GPA, along with this term interacted with gender. Main coefficient estimates are again unaffected. The estimates reveal that high-GPA women were less likely to participate.

\footnotetext{
${ }^{16}$ The average college-educated American women has her first child at the age of 30.3 (Bui \& Miller, 2018). We did not find a definitive source of the distribution over time, but results are insensitive to shifting this age range by 3 years on upper or lower bounds. Note, in this cross-section, the age is also the graduation cohort - and therefore open to multiple interpretations.
} 


\section{Field Controls}

In the earlier review and discussion of Section 2.3, prior descriptive studies point to the possibility of gender and social factors playing some role in attitudes to competition and collaboration. To attempt to detect evidence that such factors might somehow explain our main findings of fact, consider that $\%$ Female Field may somehow explain our results. Given this variable is correlated with STEM fields, we first estimate relationships with this variable in model (6).

The results presented in model (6) are striking. We find a strong relationship between participation and $\%$ Female Field $\times$ Female. Figure 2 graphically presents this relationship in a simple descriptive plot between genderedness of fields and differences in participation between women and men. Female participation is significantly greater among women in male-dominated fields. Plotting this relationship for subfield (majors) in Figure 3 reveals a similar pattern.

$<$ Figure 2 $>$

$<$ Figure 3 $>$

Allowing for the highly significant relationship in the full model, in model (7), shows that main results are entirely robust to accounting for this strong relationship with \% Female Field. It is also the case that the relationship between overall levels of female participation and gender composition is unaffected. To make this point even more clearly, Table 8 re-states these same results in the form of stratified regressions on STEM and non-STEM subsamples. The main coefficient results appear to be remarkably similar to those of models (5) and (6) of Table 5, while at the same time there appears to be a strong negative relationship between $\%$ Female Field $\times$ Female in both STEM and non-STEM fields.

$<$ Table 8> 


\section{Discussion}

\subsection{Interpretation of Main Results: Responses to Competition}

The preceding results diverge from most past studies gender differences on attitudes to competition, which document differences in average responses of male and female subjects in response to competition. (We were, ourselves, able to replicate findings by comparing mean differences in pooled comparisons.)

\section{Behavioral Similarities of Men and Women in Technical Fields}

The earlier literature review (Section 2.3) suggested two possible explanations for why gender differences in responses to competition could be attenuated in technical fields. One explanation suggests that men's and women's confidence and self-efficacy — both antecedents to attitudes to competition — might be more similar in technical fields than in other areas (e.g., Beyer \& Haller, 2006; Nekby et al., 2008). This is consistent with the responses to competition here being statistically identical. Consistent with divergences from this pattern outside of technical fields, the particular form of differences between men and women outside of STEM fields is consistent with men in non-STEM fields behaving with over-confidence. Despite having a clear disadvantage in tech-related competition (not being STEM-trained), non-STEM males were statistically equally likely to participate under Competition and Collaboration treatments (cf. Niederle \& Vesterlund, 2007).

Perhaps better reflecting an expectation of greater prospects of success when collaborating, women in non-STEM fields, and both men and women in STEM fields were more likely to participate under the Collaboration treatment. This especially stands to reason in the case of the Internet of Things, given that the scope of technologies and skills required will tend to mean that no single person will tend to be expert in each.

Also standing to reason, the negative effect of competition on females in non-STEM fields $(-27 \%)$ was more pronounced than the negative effect on males and females in STEM (-21\% and $-19 \%)$. We should expect that a rational individual from a non-STEM field would be more conservative in entering a techrelated product development project without collaboration from others. The preference for the Collaborative 
treatment over the Competitive treatment among those in STEM fields is itself consistent with these individuals having enough awareness of the Internet of Things to understand it is an area in which many sorts of skills need to be combined and the benefits of working with others (cf. Dargnies, 2012). Men and women with common technical training might also be expected to have a similar belief about how well their skills might apply to a new tech opportunity, as the Internet of Things.

\section{Ambivalence to Competition and Collaboration in Tech Fields}

A second explanation suggested from prior literature (Section 2.3), is that women could experience complex and possibly ambivalent attitudes towards competition (and collaboration) in highly-gendered environments where they encounter stereotypes (e.g., Cech et al., 2011; Cheryan et al., 2017; Choi, 2013; Foor et al., 2013; McIlwee \& Robinson, 1992; Moss-Racusin et al., 2018; Silbey, 2015, 2016b). We did find a strong association between female participation in a field and whether the field was either maledominated or female-dominated. However, we found no evidence that this association could explain or explain away the patterns related to the effect of the Competition treatment. ${ }^{17}$

\subsection{A Secondary Finding: Female Participation in Male-Dominated Fields}

Although secondary to our main research questions, the finding of a strong association between female:male participation in a field and whether a field is male- or female-dominated (Figures 2 and 3 ) in this tech-related product development activity is itself noteworthy. Females in male-dominated fields were more likely to participate than their male counterparts. The opposite is true in female-dominated fields. Remarkably, this result holds for both STEM and non-STEM fields, as in models (1) and (2) of Table 8. Female participation (conditional on field) is even better predicted by gender composition (\% Female Field $\times$ Female $)$ than it is by whether the field is technical or not (STEM Field $\times$ Female). The association between female participation and gender composition of field also appears to be unrelated to the Competition treatment effects, given including this factor as a control has no effect on main results, i.e.,

\footnotetext{
${ }^{17}$ It remains plausible that in more male dominated fields, there is increased and equal ambivalent response to both competition and to collaboration.
} 
models (6) and (7) of Table 7. A possible role played by gender socialization and peer effects-e.g., gender stereotypes, expectations, roles, and norms - has, itself, also been a suggested or conjectured in prior literature (e.g., Niederle \& Vesterlund, 2007; Rocha \& Van Praag, 2020). This predictiveness of gender composition is also analogous to Zölitz and Feld's (2018) finding that the gender composition of peers shapes men and women's choice to enter into STEM fields in the first place At the same time, it remains possible that gender composition could simply reflect some underlying field characteristic.

More generally, this striking relationship with gender composition, even controlling for the nature of fields, is consistent with the technical nature of STEM fields being an unsatisfactory explanation, on its own, of variation in participation in STEM fields. For example, female participation is lowest in Computer Science and Engineering (most relevant to tech) and Physical Sciences; but it relatively high in other STEM fields, including Chemistry, Biology and Math degrees (National Science Foundation, 2014). Even within given STEM fields, there are large differences across countries, with a larger gender gap in the US and Western Europe than is found in certain countries of Eastern Europe and Asia (Mellström, 2009; Stoet et al., 2016). Even within particular STEM fields in particular countries, we see considerable variation in gender gaps over time, as is famously the case in Computer Science where women once dominated (Abbate, 2003, 2012).

\subsection{Implications of Experimental Design}

The results also reveal the importance of refinements in experimental research design. The research design closely built on advances of past research designs (Flory et al., 2015; Niederle \& Vesterlund, 2007), while redefining details of the experimental protocol and study population that allowed us to engage in experimentation at scale (Muralidharan \& Niehaus, 2017). More importantly, here we are able to study within-sample variation across heterogeneous subjects in different fields. This is especially relevant as sorting in our experiment into a tech-related field is preceded by subjects having themselves sorted into technical and non-technical related fields.

In Section 5.1, we began by effectively replicating past results within pooled data, showing that mean proportional responses of men and women to competition differed, as in the past literature. This is 
especially important as it suggests we would have simply found similar results as past research had we either run an identical experiment as a small lab study and not been able to meaningfully probe heterogeneity (even if in a perfectly representative sample). Equally, had we focused on a single narrow sector of the labor market in the field, and particularly in non-STEM labor markets, we should not have found the results reported here. It is by including both subjects in STEM fields and those in non-STEM fields, we most explicitly reveal the contrast represented here.

\section{Conclusions}

Prior research has reported systematic differences in men and women's responses to competition in lab and several field contexts. This paper sought to understand whether these past results could be extrapolated to understand the propensity of men and women to sort into notoriously competitive organizational environments of tech firms. The field experiment reported here built on the prior research while featuring a tech-related product development activity. We also refined details of experimental protocols and subject sampling to allow to test for differences among those in both technically-related STEM fields and non-STEM fields.

We find that women in non-STEM fields respond significantly more negatively than their male counterparts to the Competition treatment (amounting to $-27 \%$ change in rates for females and no statististically signficiant change in the participation of males). By contrast, in STEM fields, women and men's responses to the Competition treatment are statistically identical (amounting to a $-19 \%$ change in rates for women and $-21 \%$ change in rates for men). These basic patterns were robust to controls for age and cohort, GPA and a measure of opportunity costs, and variation in gender composition across fields.

Of the interpretations suggested by the literature for main results, as we discussed in the previous section, the theory that most straightforwardly explains the patterns is that men and women in STEM are more similar in levels of self-confidence and self-efficacy — both antecedents to responses to competitionthan are men and women in the wider population in non-STEM fields (e.g., Beyer \& Haller, 2006; Nekby 
et al., 2008). Within this interpretation, the responses to competition are consistent among men in nonSTEM fields are consistent with exhibiting overconfidence (cf. Niederle \& Vesterlund, 2007).

The organizational implications of these findings must be approached with some caution. The most direct reading of the results does not offer any immediate suggestion that the large one-in-five gender gap in tech (see Introduction) is be explained by gender differences in attitudes to competition. The magnitudes of effects here are much smaller than the one-in-five and center on those in non-STEM fields, altogether.

On the other hand, if we consider that the study population has sorted itself into technical and nontechnical fields prior to the experiment, it might not be surprising to find that those who had sorted to STEM fields respond similarly, whereas women in non-STEM fields are more averse to competition. This could be the case if STEM fields are more competitive and competitiveness is a basis for sorting. This could also be the case through socialization within field. This explanation is perhaps closest to prior interpretations of women being tending to be more averse to competition than are men (Croson \& Gneezy, 2009), while allowing for some degree of heterogeneity in the population. In this interpretation, gender sorting and competition plays out within long-run patterns of gender sorting and separation (Glass et al., 2013; Kahn \& Ginther, 2017). Effective interventions, in this case, would be those that somehow address lifelong sorting and separation processes, where prominence of competition could be salient. Isolated policy interventions or organizational re-designs by tech firms - who encounter workers well into the lifelong process of sorting and separation - could have little systematic effect on the gender gap in tech. From a firm strategic perspective, however, there might be scope for at least competing for a subset of workers on the basis of differentiated organizational approaches_-given the results here suggest there could be considerable heterogeneity in workers' willingness to work under competition or cooperation (cf. Boudreau \& Lakhani, 2011).

At the same time, we wish to emphasize that the greater aversion to competition among non-STEM women (relative to STEM men and women) could simply be viewed as perfectly sensible — given that competing outside of one's field should typically be expected to bring worse outcomes. This interpretation 
shines a brighter light on the question of why men in non-STEM fields are indifferent to competition, and seemingly over-confident.

\section{Limitations \& Future Research}

The greatest strength of this study was in documenting cross-field and within-gender heterogeneity in responses to competition. However, beyond the findings of fact, our theoretical interpretations, much like those in prior research, rise only to a level of claiming consistency with certain explanations. Clearly studies that might add still more observable individual characteristics might have provided incrementally greater insights. However, we speculate that it may require far more discerning experimental studies focused on micro-behavioral mechanisms with novel measurement strategies or additional rich descriptive case studies and ethnographic investigations to better ascertain what is truly going on in the minds of subjects.

Another question we are left with here is whether the results we observe are inherently related to the link between the tech-related task and its greater relevance to technically-trained subjects - or is it simply relevant that the task requires relevant knowledge that the technically-trained subjects possess. For example, would we find similar results had we considered, say, dentists and non-dentists working on dentistry problems — or nurses and non-nurses working on a nursing problem? More precise understanding of mechanisms may require confronting these issues.

Another more fundamental limitation of empirical research on gender, as here, is the use and interpretation of an indicator variable to measure differences between men and women. Any use of a gender indicator variable — whether in an RCT or otherwise - cannot possibly unambiguously measure a "gender effect," or any sort of all-else-being-equal comparison between men and women (Holland, 1986). Gender will be closely intertwined with an array of other personal characteristics shaping outcomes. Simply adding "control" variables cannot wholly truly control for possible spurious effects (Oster, 2019). And therefore, the results here, as in other empirical research on gender, must be read with great caution and with the suspicion that reported coefficients reflect factors other than just the sex of subjects. 


\section{References}

Ancona, D. G., \& Caldwell, D. F. (1992). Demography and design: Predictors of new product team performance. Organization Science, 3(3), 321-341.

Andersen, S., Ertac, S., Gneezy, U., List, J. A., \& Maximiano, S. (2013). Gender, competitiveness, and socialization at a young age: Evidence from a matrilineal and a patriarchal society. Review of Economics and Statistics, 95(4), 1438-1443.

Apicella, C. L., Demiral, E. E., \& Mollerstrom, J. (2017). No gender difference in willingness to compete when competing against self. American Economic Review, 107(5), 136-40.

Bear, J. B., \& Woolley, A. W. (2011). The role of gender in team collaboration and performance. Interdisciplinary Science Reviews, 36(2), 146-153.

Bertrand, M., \& Hallock, K. F. (2001). The gender gap in top corporate jobs. ILR Review, 55(1), 3-21.

Beyer, S., \& Haller, S. (2006). Gender differences and intragender differences in computer science students: Are female CS majors more similar to male CS majors or female nonmajors? Journal of Women and Minorities in Science and Engineering, 12(4).

Blevins, D. P., Sauerwald, S., Hoobler, J. M., \& Robertson, C. J. (2019). Gender Differences in Pay Levels: An Examination of the Compensation of University Presidents. Organization Science, 30(3), 600616.

Boaler, J. (2016). Mathematical mindsets: Unleashing students' potential through creative math, inspiring messages and innovative teaching. John Wiley \& Sons.

Booth, A., Fan, E., Meng, X., \& Zhang, D. (2019). Gender differences in willingness to compete: The role of culture and institutions. The Economic Journal, 129(618), 734-764.

Boudreau, K. J., \& Lakhani, K. R. (2011). The confederacy of heterogeneous software organizations and heterogeneous developers: Field experimental evidence on sorting and worker effort. In The rate and direction of inventive activity revisited (pp. 483-502). University of Chicago Press.

Brynjolfsson, E., \& Mcafee, A. (2014). The Second Machine Age: Work, Progress, and Prosperity in a Time of Brilliant Technologies. W. W. Norton \& Company.

Bui, Q., \& Miller, C. (2018). The Age That Women Have Babies: How a Gap Divides America. The New York Times.

Buser, T. (2009). The impact of female sex hormones on competitiveness. Tinbergen Institute Discussion Paper.

Buser, T., Peter, N., \& Wolter, S. C. (2017). Gender, competitiveness, and study choices in high school: Evidence from Switzerland. American Economic Review, 107(5), 125-30.

Castilla, E. J. (2015). Accounting for the gap: A firm study manipulating organizational accountability and transparency in pay decisions. Organization Science, 26(2), 311-333.

Cech, E., Rubineau, B., Silbey, S., \& Seron, C. (2011). Professional role confidence and gendered persistence in engineering. American Sociological Review, 76(5), 641-666.

Ceci, S. J., Ginther, D. K., Kahn, S., \& Williams, W. M. (2014). Women in academic science: A changing landscape. Psychological Science in the Public Interest, 15(3), 75-141.

Chang, E. (2018). Brotopia: Breaking Up the Boys' Club of Silicon Valley. Portfolio.

Cheryan, S., Ziegler, S. A., Montoya, A. K., \& Jiang, L. (2017). Why are some STEM fields more gender balanced than others? Psychological Bulletin, 143(1), 1.

Choi, K. S. (2013). Evaluating gender significance within a pair programming context. 2013 46th Hawaii International Conference on System Sciences, 4817-4825. 
Comeig, I., Grau-Grau, A., Jaramillo-Gutiérrez, A., \& Ramírez, F. (2016). Gender, self-confidence, sports, and preferences for competition. Journal of Business Research, 69(4), 1418-1422.

Correll, S. J. (2001). Gender and the career choice process: The role of biased self-assessments. American Journal of Sociology, 106(6), 1691-1730.

Croson, R., \& Gneezy, U. (2009). Gender differences in preferences. Journal of Economic Literature, 47(2), 448-74.

Dargnies, M.-P. (2012). Men too sometimes shy away from competition: The case of team competition. Management Science, 58(11), 1982-2000.

Dreber, A., Von Essen, E., \& Ranehill, E. (2011). Outrunning the gender gap-Boys and girls compete equally. Experimental Economics, 14(4), 567-582.

Ellis, J., Fosdick, B. K., \& Rasmussen, C. (2016). Women 1.5 times more likely to leave STEM pipeline after calculus compared to men: Lack of mathematical confidence a potential culprit. PloS One, $11(7), \mathrm{e} 0157447$.

Evetts, J. (1996). Gender and career in science and engineering (Vol. 2). CRC Press.

Fernandez, R. M., \& Campero, S. (2017). Gender sorting and the glass ceiling in high-tech firms. ILR Review, 70(1), 73-104.

Fernandez-Mateo, I., \& Kaplan, S. (2018). Gender and organization science: Introduction to a virtual special issue. Organization Science, 29(6), 1229-1236.

Flory, J. A., Gneezy, U., Leonard, K. L., \& List, J. A. (2018). Gender, age, and competition: A disappearing gap? Journal of Economic Behavior \& Organization, 150, 256-276. https://doi.org/10.1016/j.jebo.2018.03.027

Flory, J. A., Leibbrandt, A., \& List, J. A. (2015). Do competitive workplaces deter female workers? A largescale natural field experiment on job entry decisions. The Review of Economic Studies, 82(1), 122155.

Foor, C. E., Walden, S. E., Shehab, R. L., \& Trytten, D. A. (2013). "We weren't intentionally excluding them... just old habits": Women,(lack of) interest and an engineering student competition team. 2013 IEEE Frontiers in Education Conference (FIE), 349-355.

Friesel, A., \& Timcenko, O. (2011). Competition-motivated teamwork and narratives to motivate girls for engineering. 22nd EAEEIE Annual Conference.

Glass, J. L., Sassler, S., Levitte, Y., \& Michelmore, K. M. (2013). What's so special about STEM? A comparison of women's retention in STEM and professional occupations. Social Forces, 92(2), 723-756.

Gneezy, U., Niederle, M., \& Rustichini, A. (2003). Performance in competitive Environments: Gender differences. The Quarterly Journal of Economics, 118, 1049-1074.

Günther, C., Ekinci, N. A., Schwieren, C., \& Strobel, M. (2010). Women can’t jump?-An experiment on competitive attitudes and stereotype threat. Journal of Economic Behavior \& Organization, 75(3), 395-401.

Guzman, J., \& Kacperczyk, A. O. (2019). Gender gap in entrepreneurship. Research Policy, 48(7), 16661680.

Harris, J., \& Alter, A. (2016). Corporate Culture: California Dreaming. Accenture Briefing.

Herring, C. (2009). Does diversity pay?: Race, gender, and the business case for diversity. American Sociological Review, 74(2), 208-224.

Holland, P. W. (1986). Statistics and causal inference. Journal of the American Statistical Association, 81(396), 945-960. 
Iriberri, N., \& Rey-Biel, P. (2019). Competitive pressure widens the gender gap in performance: Evidence from a two-stage competition in mathematics. The Economic Journal, 129(620), 1863-1893.

Isaac, M. (2017, February 22). Inside Uber's Aggressive, Unrestrained Workplace Culture. New York Times.

Jang, S. (2017). Cultural brokerage and creative performance in multicultural teams. Organization Science, 28(6), 993-1009.

Jurajda, Š., \& Münich, D. (2011). Gender gap in performance under competitive pressure: Admissions to Czech universities. American Economic Review, 101(3), 514-18.

Kahn, S., \& Ginther, D. (2017). Women and STEM. National Bureau of Economic Research.

Kneeland, M. K., Schilling, M. A., \& Aharonson, B. S. (2020). Exploring Uncharted Territory: Knowledge Search Processes in the Origination of Outlier Innovation. Organization Science.

Knight, J. (2002). Sexual stereotypes. Nature Publishing Group.

Kuhn, P., \& Villeval, M. C. (2015). Are women more attracted to co-operation than men? The Economic Journal, 125(582), 115-140.

Kuyath, S. J., \& Yoder, L. (2004). Diversity in Engineering Technology: Competitions. Age, 9, 1.

Lambrecht, A., \& Tucker, C. E. (2018). Algorithmic bias? An empirical study into apparent gender-based discrimination in the display of STEM career ads. An Empirical Study into Apparent Gender-Based Discrimination in the Display of STEM Career Ads (March 9, 2018).

Lippa, R. (1998). Gender-related individual differences and the structure of vocational interests: The importance of the people-things dimension. Journal of Personality and Social Psychology, 74(4), 996.

Marra, R. M., \& Bogue, B. (2006). Women engineering students' self efficacy-a longitudinal multiinstitution study. Women in Engineering ProActive Network.

McAfee, A., \& Brynjolfsson, E. (2018). Machine, Platform, Crowd: Harnessing Our Digital Future (1 edition). W. W. Norton \& Company.

McIlwee, J. S., \& Robinson, J. G. (1992). Women in engineering: Gender, power, and workplace culture. SUNY Press.

Morin, L.-P. (2015). Do men and women respond differently to competition? Evidence from a major education reform. Journal of Labor Economics, 33(2), 443-491.

Moss-Racusin, C. A., Sanzari, C., Caluori, N., \& Rabasco, H. (2018). Gender bias produces gender gaps in STEM engagement. Sex Roles, 79(11-12), 651-670.

Muralidharan, K., \& Niehaus, P. (2017). Experimentation at scale. Journal of Economic Perspectives, 31(4), 103-24.

Murciano-Goroff, R. (2018). Missing women in tech: The labor market for highly skilled software engineers. Work in Progress. Http://Stanford. Edu/ Ravivmg/Papers/JMP. Pdf.

Nekby, L., Thoursie, P. S., \& Vahtrik, L. (2008). Gender and self-selection into a competitive environment: Are women more overconfident than men? Economics Letters, 100(3), 405-407.

Niederle, M., \& Vesterlund, L. (2007). Do Women Shy Away from Competition? Do Men Compete Too Much? Quarterly Journal of Economics, 122(3), 1067-1101.

Niederle, M., \& Vesterlund, L. (2011). Gender and competition. Annu. Rev. Econ., 3(1), 601-630.

Nielsen, M. W., Bloch, C. W., \& Schiebinger, L. (2018). Making gender diversity work for scientific discovery and innovation. Nature Human Behaviour, 2(10), 726-734.

Nosek, B. A., Smyth, F. L., Sriram, N., Lindner, N. M., Devos, T., Ayala, A., Bar-Anan, Y., Bergh, R., Cai, H., \& Gonsalkorale, K. (2009). National differences in gender-science stereotypes predict national 
sex differences in science and math achievement. Proceedings of the National Academy of Sciences, 106(26), 10593-10597.

Notter, K. B. (2010). Is competition making a comeback? Discovering methods to keep female adolescents engaged in STEM: A phenomenological approach.

NSCRC. (2017). Snapshot Report Science and Engineering Degree Completion by Gender, National Student Clearinghouse Research Center. https://nscresearchcenter.org/wpcontent/uploads/SnapshotReport27r.pdf

Ors, E., Palomino, F., \& Peyrache, E. (2013). Performance gender gap: Does competition matter? Journal of Labor Economics, 31(3), 443-499.

Oster, E. (2019). Unobservable selection and coefficient stability: Theory and evidence. Journal of Business \& Economic Statistics, 37(2), 187-204.

Paserman, M. D. (2010). Gender Differences in Performance in Competitive Environments? Evidence from Professional Tennis Players.

Patel, M., Shangkuan, J., \& Thomas, C. (2017). What's new with the Internet of Things? McKinsey \& Company. https://www.mckinsey.com/industries/semiconductors/our-insights/whats-new-withthe-internet-of-things

Reuben, E., Sapienza, P., \& Zingales, L. (2015). Taste for Competition and the Gender Gap Among Young Business Professionals. NBER Working Paper No. 21695.

Rocha, V., \& Van Praag, M. (2020). Mind the gap: The role of gender in entrepreneurial career choice and social influence by founders. Strategic Management Journal.

Schwab, K. (2017). The fourth industrial revolution. Currency.

Scott, E. L., \& Shu, P. (2017). Gender gap in high-growth ventures: Evidence from a university venture mentoring program. American Economic Review, 107(5), 308-11.

Sherf, E. N., Tangirala, S., \& Weber, K. C. (2017). It is not my place! Psychological standing and men's voice and participation in gender-parity initiatives. Organization Science, 28(2), 193-210.

Shurchkov, O. (2012). Under pressure: Gender differences in output quality and quantity under competition and time constraints. Journal of the European Economic Association, 10(5), 1189-1213.

Silbey, S. S. (2015). The elephant in the room: Constraints and consequences of a four-year undergraduate engineering degree. Engineering Studies, 7(2-3), 164-167.

Silbey, S. S. (2016a). Why do so many women who study engineering leave the field. Harvard Business Review, 1-2.

Silbey, S. S. (2016b). Why do so many women who study engineering leave the field. Harvard Business Review, 1-2.

Slack Website. (2019). In good company: How to create a culture of collaboration at work. https://slackhq.com/culture-collaboration-work

Snyder, K. (2017). 1000 different people, the same words: What hiring language from 25,000 recent job descriptions tells us about corporate cultural norms. Medium. https://medium.com/textio/1000different-people-the-same-words-6149b5a1f351

Sutter, M., \& Glätzle-Rützler, D. (2015). Gender differences in the willingness to compete emerge early in life and persist. Management Science, 61(10), 2339-2354.

Tang, T. (2019). Sources of Girls' Math Self-Efficacy Beliefs.

Trajtenberg, M. (2019). Artificial Intelligence as the Next GPT. The Economics of Artificial Intelligence: An Agenda, 175. 
US BLS. (2017). Trends among native- and foreign-origin workers in U.S. computer industries. United States Bureau of Labor Statistics. https://www.bls.gov/opub/mlr/2017/article/trends-amongnative-and-foreign-origin-workers-in-us-computer-industries.htm

Wieland, A., \& Sarin, R. (2012). Domain specificity of sex differences in competition. Journal of Economic Behavior \& Organization, 83(1), 151-157.

Wynn, A. T., \& Correll, S. J. (2017). Gendered perceptions of cultural and skill alignment in technology companies. Social Sciences, 6(2), 45.

Zhang, L. (2020). An institutional approach to gender diversity and firm performance. Organization Science, 31(2), 439-457.

Zölitz, U., \& Feld, J. (2018). The effect of peer gender on major choice. University of Zurich, Department of Economics, Working Paper, 270. 


\section{Tables}

Table 1 Descriptive Statistics of Main Variables

\begin{tabular}{|c|c|c|c|c|}
\hline Variable & No. Obs. & Mean & Std. Dev. & Description \\
\hline Participation & 97,696 & 2.85 & 16.65 & $\begin{array}{l}\text { Indicator for choosing to participate in } \\
\text { the activity (multiplied by 100) }\end{array}$ \\
\hline Competition & 97,696 & 0.50 & 0.50 & Treatment effect indicator \\
\hline Female & 97,696 & 0.44 & 0.50 & Sex Indicator \\
\hline STEM & 97,696 & 0.33 & 0.47 & $\begin{array}{l}\text { Indicator switched on if field is } \\
\text { Computer Science, Engineering, or }\end{array}$ \\
\hline Student & 97,696 & 0.08 & 0.27 & $\begin{array}{l}\text { Indicator switched on for currently- } \\
\text { enrolled students, as opposed to alumni } \\
\text { graduates }\end{array}$ \\
\hline Graduation Year & 97,696 & 1999 & 16 & Year of graduation \\
\hline GPA & 36,345 & 3.01 & 1.17 & $\begin{array}{l}\text { Cumulative undegraduate grade point } \\
\text { average (available for those graduating } \\
2009 \text { or later) }\end{array}$ \\
\hline No. Clubs & 8,590 & 1.25 & 1.84 & $\begin{array}{l}\text { Count of number of clubs and } \\
\text { extracurricular activities listed on } \\
\text { Linkedin listings (available for those } \\
\text { graduating after } 2015 \text { and matched) }\end{array}$ \\
\hline
\end{tabular}


Table 2 Study Population by Field and Graduation Year

I.

\begin{tabular}{lrc}
\hline \hline Field & \multicolumn{1}{c}{$\mathrm{N}$} & Females : Total \\
\hline Business & 24,571 & $36 \%$ \\
Computer Science & 3,595 & $26 \%$ \\
Design \& Media & 6,536 & $61 \%$ \\
Engineering & 20,067 & $19 \%$ \\
Health Science \& & 16,677 & $77 \%$ \\
Nursing & & \\
Humanities & 13,931 & $49 \%$ \\
Law & 3,683 & $57 \%$ \\
Sciences & 8,636 & $56 \%$ \\
\hline Total & 97,696 & $45 \%$ \\
\hline \hline
\end{tabular}

II.

\begin{tabular}{lcc}
\hline \hline $\begin{array}{l}\text { Decade of } \\
\text { Graduation }\end{array}$ & $\mathrm{N}$ & Females : Total \\
\hline$<1960$ & 1,253 & $9 \%$ \\
$1960 \mathrm{~s}$ & 3,936 & $15 \%$ \\
$1970 \mathrm{~s}$ & 9,037 & $30 \%$ \\
$1980 \mathrm{~s}$ & 11,864 & $41 \%$ \\
$1990 \mathrm{~s}$ & 11,495 & $45 \%$ \\
$2000 \mathrm{~s}$ & 19,530 & $52 \%$ \\
$>2010$ & 40,581 & $49 \%$ \\
\hline Total & 97,696 & $45 \%$ \\
\hline \hline
\end{tabular}


Table 3 Comparison of Treatment and Control Groups

\begin{tabular}{lccc}
\hline \hline Variable & $\begin{array}{c}\text { Competition } \\
\text { Treatment }\end{array}$ & $\begin{array}{c}\text { Collaboration } \\
\text { Treatment }\end{array}$ & $\begin{array}{c}\text { Standard } \\
\text { Deviation }\end{array}$ \\
\hline Female & $44 \%$ & $45 \%$ & $50 \%$ \\
STEM & $33 \%$ & $33 \%$ & $47 \%$ \\
GPA & 3.0 & 3.0 & 1.2 \\
Student & $8 \%$ & $8 \%$ & $27 \%$ \\
$\%$ Females in Field & $45 \%$ & $45 \%$ & $20 \%$ \\
Age & 37.8 & 37.7 & 16.2 \\
Business & $25 \%$ & $25 \%$ & $43 \%$ \\
Computer Science & $4 \%$ & $4 \%$ & $19 \%$ \\
Engineering & $20 \%$ & $21 \%$ & $40 \%$ \\
Health Studies \& Nurs & $17 \%$ & $17 \%$ & $37 \%$ \\
Humanities & $14 \%$ & $14 \%$ & $35 \%$ \\
Law & $4 \%$ & $4 \%$ & $19 \%$ \\
Media \& Design & $7 \%$ & $7 \%$ & $25 \%$ \\
Sciences & $9 \%$ & $9 \%$ & $28 \%$ \\
\hline
\end{tabular}


Table 4 Baseline (Aggregate Population Average) OLS Linear Probability Estimates of Gender Differences \& Treatment Effect

\begin{tabular}{|c|c|c|c|c|c|c|c|c|}
\hline \multirow{3}{*}{$\begin{array}{r}\text { Dep. Var.: } \\
\text { Model: }\end{array}$} & \multicolumn{7}{|c|}{ Participation [Percentage Points] } & \multirow{2}{*}{$\frac{\text { No. Clubs }}{(8)}$} \\
\hline & (1) & (2) & (3) & (4) & (5) & (6) & (7) & \\
\hline & Gender & Treatment & Interaction & $\begin{array}{c}\text { Day } \\
\text { Assignment }\end{array}$ & $\begin{array}{l}\text { Students v. } \\
\text { Graduates }\end{array}$ & Cohort & $\begin{array}{l}\text { Clubs Data } \\
\text { Subsample }\end{array}$ & Placebo \\
\hline Female & $\begin{array}{c}-0.67 * * * \\
(0.11)\end{array}$ & $\begin{array}{c}-0.67 * * * \\
(0.11)\end{array}$ & $\begin{array}{c}-0.67 * * * \\
(0.16)\end{array}$ & $\begin{array}{c}-0.67 * * * \\
(0.16)\end{array}$ & $\begin{array}{c}-0.81 * * * \\
(0.16)\end{array}$ & $\begin{array}{c}-1.13 * * * \\
(0.16)\end{array}$ & $\begin{array}{c}-2.64 * * * \\
(0.91)\end{array}$ & $\begin{array}{c}0.38 * * * \\
(0.06)\end{array}$ \\
\hline Competition & & $\begin{array}{c}-0.71 * * * \\
(0.11)\end{array}$ & $\begin{array}{c}-0.71 * * * \\
(0.15)\end{array}$ & $\begin{array}{c}-0.71 * * * \\
(0.15)\end{array}$ & $\begin{array}{c}-0.73 * * * \\
(0.15)\end{array}$ & $\begin{array}{c}-0.74 * * * \\
(0.15)\end{array}$ & $\begin{array}{c}-2.12 * * \\
(0.93)\end{array}$ & $\begin{array}{l}-0.06 \\
(0.05)\end{array}$ \\
\hline Female $\times$ Comp & etition & & $\begin{array}{c}0.00 \\
(0.21)\end{array}$ & $\begin{array}{l}-0.01 \\
(0.21)\end{array}$ & $\begin{array}{c}0.02 \\
(0.21)\end{array}$ & $\begin{array}{c}0.01 \\
(0.21)\end{array}$ & $\begin{array}{c}0.46 \\
(1.23)\end{array}$ & $\begin{array}{l}-0.10 \\
(0.08)\end{array}$ \\
\hline Student & & & & & $\begin{array}{c}6.75 * * * \\
(0.33)\end{array}$ & & & \\
\hline Constant & $\begin{array}{c}3.19 * * * \\
(0.08)\end{array}$ & $\begin{array}{c}3.54 * * * \\
(0.10)\end{array}$ & $\begin{array}{c}3.54 * * * \\
(0.11)\end{array}$ & $\begin{array}{c}2.76 * * * \\
(0.38)\end{array}$ & $\begin{array}{c}3.08 * * * \\
(0.11)\end{array}$ & $\begin{array}{c}0.74 * * * \\
(0.15)\end{array}$ & $\begin{array}{c}10.94 * * * \\
(0.69)\end{array}$ & $\begin{array}{c}1.12 * * * \\
(0.04)\end{array}$ \\
\hline Day FEs & & & & $\mathrm{Y}$ & & & & \\
\hline Grad Year FEs & & & & & & Y & & \\
\hline Adjusted $R^{\wedge} 2$ & 0.001 & 0.001 & 0.001 & 0.001 & 0.012 & 0.019 & 0.003 & 0.009 \\
\hline Statistica & $\begin{array}{l}\text { emale comp } \\
\text { avg female }\end{array}$ & $\begin{array}{l}\text { tition effect : } \\
\text { articipation }\end{array}$ & $-25 \%$ & $-25 \%$ & $-32 \%$ & $-31 \%$ & $-26 \%$ & $\mathrm{n} / \mathrm{a}$ \\
\hline Statistic & $\begin{array}{r}\text { male comp } \\
\text { avg male }\end{array}$ & $\begin{array}{l}\text { tition effect: } \\
\text { articipation }\end{array}$ & $-20 \%$ & $-20 \%$ & $-24 \%$ & $-21 \%$ & $-19 \%$ & $\mathrm{n} / \mathrm{a}$ \\
\hline
\end{tabular}

Note. OLS Linear probability model coefficients are reported as percentage points. Heteroskedasticity-robust standard errors reported in brackets. $* * * \mathrm{p}<0.01,{ }^{* *}$ $\mathrm{p}<0.05, * \mathrm{p}<0.1$. No. observations $=92,678$. The variable \% Females in Field is not included in the model, as it is collinear with field fixed effects. The Statistical female competition effect : avg female participation is the treatment effect, based coefficient estimates that are statistically distinguishable from zero, divided by the mean participation level of either men or women in either STEM or non-STEM fields. This denominator, mean participation levels, is directly calculated from the data (it cannot be directly read from the model, given the inclusion of many fixed effects). 
Table 5 OLS Linear Probability Estimates of Gender Differences \& Treatment Effect, Controlling for Cross-Field Differences

\begin{tabular}{|c|c|c|c|c|}
\hline \multirow{2}{*}{$\begin{array}{r}\text { Dep. Var.: } \\
\text { Model: }\end{array}$} & \multicolumn{4}{|c|}{ Participation [Percentage Points] } \\
\hline & $\begin{array}{c}\text { (1) } \\
\text { Population } \\
\text { Avg. }\end{array}$ & $\begin{array}{c}(2) \\
\text { Controlling } \\
\text { Fields } \\
\end{array}$ & $\begin{array}{c}\text { (3) } \\
\text { Population } \\
\text { Avg. }\end{array}$ & $\begin{array}{c}(4) \\
\text { Controlling } \\
\text { Fields }\end{array}$ \\
\hline Female & $\begin{array}{c}-0.67 * * * \\
(0.11)\end{array}$ & $\begin{array}{c}0.25 * * \\
(0.12)\end{array}$ & $\begin{array}{c}-0.67 * * * \\
(0.16)\end{array}$ & $\begin{array}{c}0.40 * * \\
(0.17)\end{array}$ \\
\hline Competition & & & $\begin{array}{c}-0.71 * * * \\
(0.15)\end{array}$ & $\begin{array}{c}-0.43 * * * \\
(0.15)\end{array}$ \\
\hline Female $\times$ Comp & etition & & $\begin{array}{c}0.00 \\
(0.21)\end{array}$ & $\begin{array}{l}-0.29 \\
(0.21)\end{array}$ \\
\hline Computer Scien & & $\begin{array}{c}7.03 * * * \\
(0.43)\end{array}$ & & $\begin{array}{c}7.25 * * * \\
(0.44)\end{array}$ \\
\hline Engineering & & $\begin{array}{c}3.96 * * * \\
(0.14)\end{array}$ & & $\begin{array}{c}4.18 * * * \\
(0.16)\end{array}$ \\
\hline Sciences & & $\begin{array}{c}2.98 * * * \\
(0.20)\end{array}$ & & $\begin{array}{c}3.18 * * * \\
(0.22)\end{array}$ \\
\hline Business & & $\begin{array}{c}2.75 * * * \\
(0.11)\end{array}$ & & $\begin{array}{c}2.96 * * * \\
(0.14)\end{array}$ \\
\hline Design \& Medic & & $\begin{array}{c}2.59 * * * \\
(0.22)\end{array}$ & & $\begin{array}{c}2.80 * * * \\
(0.24)\end{array}$ \\
\hline Humanities & & $\begin{array}{c}2.07 * * * \\
(0.14)\end{array}$ & & $\begin{array}{c}2.28 * * * \\
(0.16)\end{array}$ \\
\hline Law & & $\begin{array}{c}1.42 * * * \\
(0.22)\end{array}$ & & $\begin{array}{c}1.63 * * * \\
(0.23)\end{array}$ \\
\hline Health Science & \& Nursing & $\begin{array}{c}1.06 * * * \\
(0.13)\end{array}$ & & $\begin{array}{c}1.27 * * * \\
(0.16)\end{array}$ \\
\hline Constant & $\begin{array}{c}3.19 * * * \\
(0.08)\end{array}$ & & $\begin{array}{c}3.54 * * * \\
(0.11)\end{array}$ & \\
\hline Field FEs & & Y & & Y \\
\hline Female response & e to compe & tition: & $-25 \%$ & $-11 \%$ \\
\hline Male response $t$ & o competiti & ion: & $-20 \%$ & $-12 \%$ \\
\hline Adjusted $R^{\wedge} 2$ & 0.000 & 0.030 & 0.001 & 0.030 \\
\hline
\end{tabular}

Note. OLS Linear probability model coefficients are reported as percentage points. Heteroskedasticity-robust standard errors reported in brackets. ${ }^{* * *} \mathrm{p}<0.01,{ }^{* *} \mathrm{p}<0.05,{ }^{*} \mathrm{p}<0.1$. No. observations $=92,678$. The variable $\%$ Females in Field is not included in the model, as it is collinear with field fixed effects. The Statistical female competition effect : avg female participation is the treatment effect, based coefficient estimates that are statistically distinguishable from zero, divided by the mean participation level of either men or women in either STEM or nonSTEM fields. This denominator, mean participation levels, is directly calculated from the data (it cannot be directly read from the model, given the inclusion of many fixed effects). 
Table 6 Cross-Field Differences of Within-Field Gender Differences \& Treatment Effects

\begin{tabular}{|c|c|c|c|c|c|c|}
\hline \multirow{2}{*}{$\begin{array}{r}\text { Dep. Var.: } \\
\text { Model: }\end{array}$} & \multicolumn{6}{|c|}{ Participation [Percentage Points] } \\
\hline & (1) & $(2)$ & (3) & (4) & $(5)$ & $(6)$ \\
\hline & Baseline & \multicolumn{3}{|c|}{ STEM Interaction } & non-STEM & STEM \\
\hline Female & $\begin{array}{c}0.40 * * \\
(0.17)\end{array}$ & $\begin{array}{c}0.12 \\
(0.17)\end{array}$ & $\begin{array}{c}0.18 \\
(0.18)\end{array}$ & $\begin{array}{c}0.20 \\
(0.19)\end{array}$ & $\begin{array}{c}0.20 \\
(0.19)\end{array}$ & $\begin{array}{c}1.13 * * * \\
(0.40)\end{array}$ \\
\hline Competition & $\begin{array}{c}-0.43 * * * \\
(0.15)\end{array}$ & $\begin{array}{c}-0.42 * * * \\
(0.15)\end{array}$ & $\begin{array}{l}-0.13 \\
(0.17)\end{array}$ & $\begin{array}{l}-0.11 \\
(0.18)\end{array}$ & $\begin{array}{l}-0.11 \\
(0.18)\end{array}$ & $\begin{array}{c}-0.87 * * * \\
(0.26)\end{array}$ \\
\hline Female $\times$ Competitior & $\begin{array}{l}-0.29 \\
(0.21)\end{array}$ & $\begin{array}{l}-0.29 \\
(0.21)\end{array}$ & $\begin{array}{c}-0.43 * \\
(0.22)\end{array}$ & $\begin{array}{c}-0.47 * * \\
(0.23)\end{array}$ & $\begin{array}{c}-0.47 * * \\
(0.23)\end{array}$ & $\begin{array}{l}-0.32 \\
(0.50)\end{array}$ \\
\hline STEM Field $\times$ Female & & $\begin{array}{c}1.00 * * * \\
(0.31)\end{array}$ & $\begin{array}{c}1.01 * * * \\
(0.31)\end{array}$ & $\begin{array}{c}0.93 * * \\
(0.44)\end{array}$ & & \\
\hline \multicolumn{2}{|c|}{ STEM Field $\times$ Competition } & & $\begin{array}{c}-0.71 * * * \\
(0.26)\end{array}$ & $\begin{array}{c}-0.76 * * \\
(0.32)\end{array}$ & & \\
\hline \multicolumn{4}{|c|}{ STEM Field $\times$ Female $\times$ Competition } & $\begin{array}{c}0.15 \\
(0.55)\end{array}$ & & \\
\hline Field FEs & Y & Y & Y & $\mathrm{Y}$ & Y & Y \\
\hline \multirow[t]{3}{*}{ Adjusted $R^{\wedge} 2$} & 0.03 & 0.03 & 0.03 & 0.03 & 0.02 & 0.05 \\
\hline & \multicolumn{4}{|c|}{$\begin{array}{r}\text { Statistical female competition effect : } \\
\text { avg female participation }\end{array}$} & $-24 \%$ & $-19 \%$ \\
\hline & \multicolumn{4}{|c|}{$\begin{array}{r}\text { Statistical male competition effect : } \\
\text { avg male participation }\end{array}$} & $0 \%$ & $-22 \%$ \\
\hline
\end{tabular}

Note. OLS Linear probability model coefficients are reported as percentage points. Heteroskedasticity-robust standard errors reported in brackets. ${ }^{* * *} \mathrm{p}<0.01,{ }^{* *} \mathrm{p}<0.05, * \mathrm{p}<0.1$. No. observations $=92,678$. The variable $\%$ Females in Field is not included in the model, as it is collinear with field fixed effects. The Statistical female competition effect : avg female participation is the treatment effect, based coefficient estimates that are statistically distinguishable from zero, divided by the mean participation level of either men or women in either STEM or non-STEM fields. This denominator, mean participation levels, is directly calculated from the data (it cannot be directly read from the model, given the inclusion of many fixed effects). 
Table 7 Robustness Tests

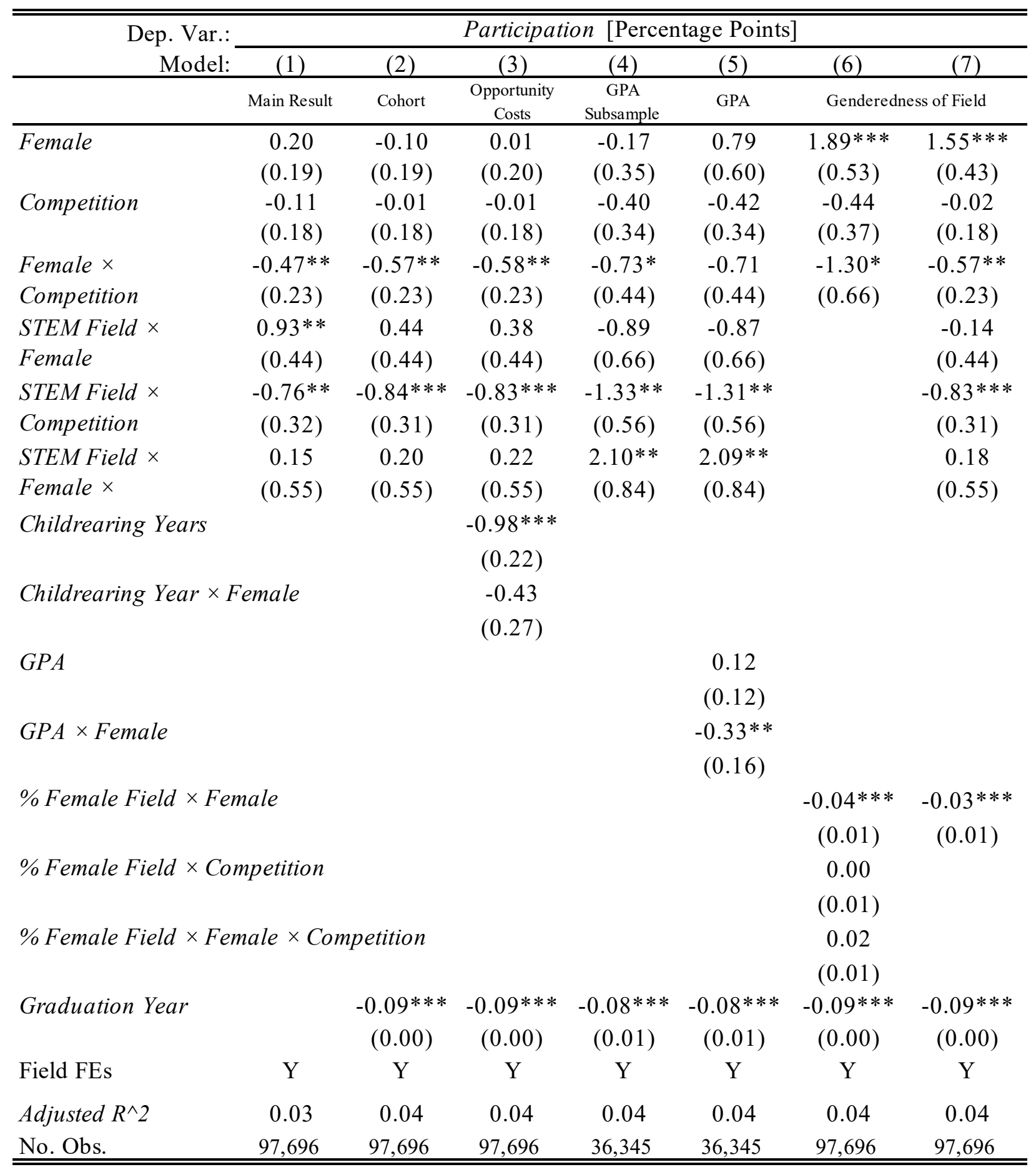


Table 8 Competition Treatment Effects by STEM and Gender, Conditional on Gender Composition of Fields

\begin{tabular}{lcc}
\hline \hline & Dep. Var.: & \multicolumn{2}{c}{ Participation } & [Percentage Points] \\
\cline { 2 - 3 } Model: & $(1)$ & $(2)$ \\
\hline Female & non-STEM Fields & STEM Fields \\
Competition & $1.19^{* *}$ & $1.64 * *$ \\
& $(0.47)$ & $(0.68)$ \\
Female $\times$ Competition & -0.05 & $-0.84 * * *$ \\
& $(0.18)$ & $(0.26)$ \\
\% Female Field $\times$ Female & $-0.54 * *$ & -0.42 \\
& $(0.23)$ & $(0.50)$ \\
Graduation Year & $-0.02 * * *$ & $-0.05 * * *$ \\
Field FEs & $(0.01)$ & $(0.01)$ \\
Adjusted $R^{\wedge} 2$ & $-0.06 * * *$ & $-0.13 * * *$ \\
No. Obs. & $(0.00)$ & $(0.01)$ \\
Statistical female competition effect & $\mathrm{Y}$ & $\mathrm{Y}$ \\
: avg female participation & $-27 \%$ & 0.06 \\
Statistical male treatment effect : & & 31,935 \\
avg male participation & 0.03 & $-19 \%$ \\
\hline \hline
\end{tabular}

Note. OLS Linear probability model coefficients are reported as percentage points. Heteroskedasticity-robust standard errors reported in brackets. ${ }^{* *} \mathrm{p}<0.01, * * \mathrm{p}<0.05, * \mathrm{p}<0.1$. No. observations $=92,678$. The variable $\%$ Females in Field is not included in the model, as it is collinear with field fixed effects. The Statistical female competition effect : avg female participation is the treatment effect, based coefficient estimates that are statistically distinguishable from zero, divided by the mean participation level of either men or women in either STEM or non-STEM fields. This denominator, mean participation levels, is directly calculated from the data (it cannot be directly read from the model, given the inclusion of many fixed effects). 


\section{Figures}

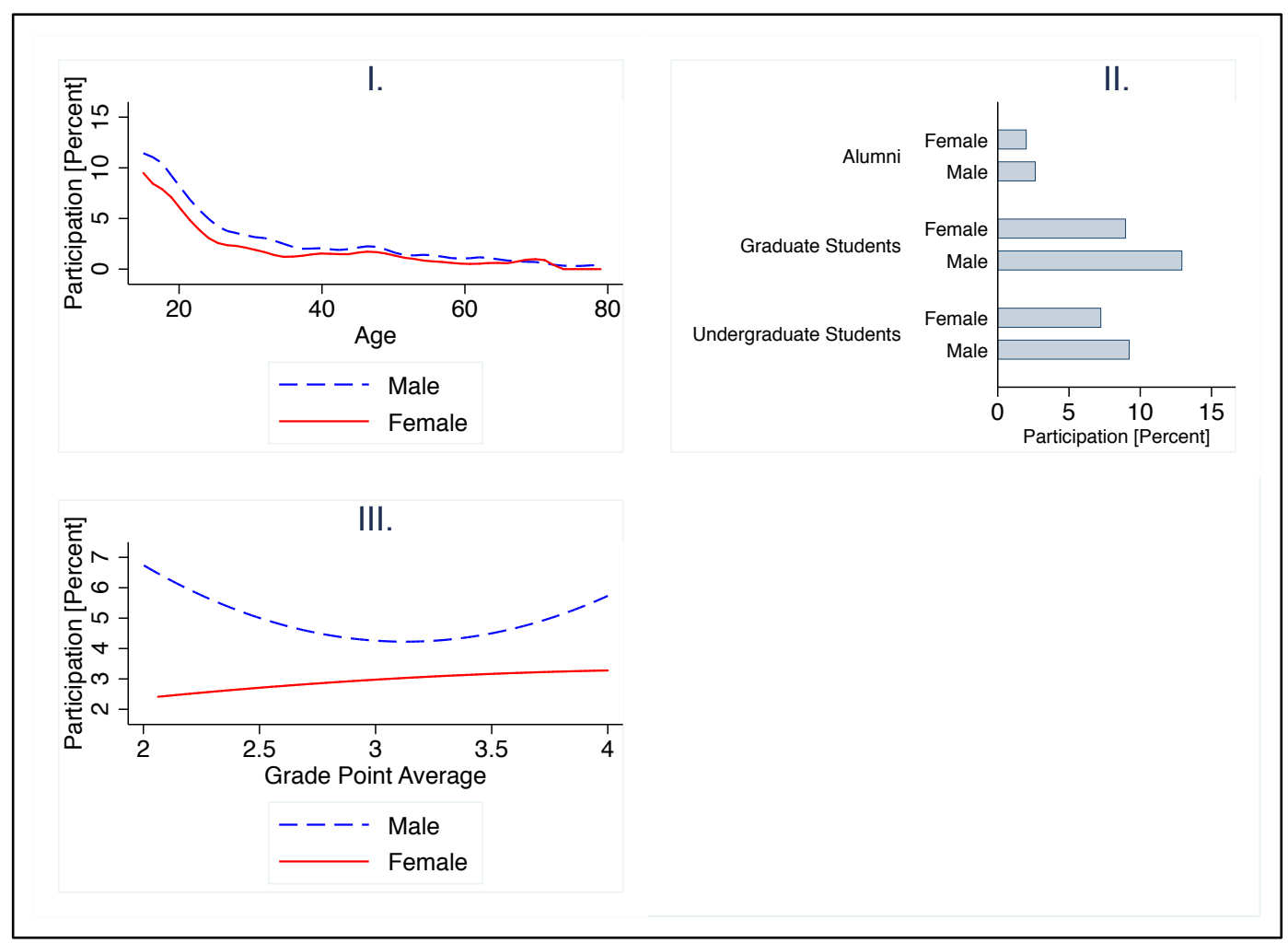

Figure 1 Gender Differences in Participation by Age, Student vs. Alumni, and GPA

Note. In Panel I Age is used rather than graduation year, in the interest of more direct interpretation. Age is based on graduation year and approximated according to the approximation that graduation occurs at the age of 22 or thereabouts. Panel III summarizes differences in participation across males and females in relation to GPA with quadratic fitted curve. 


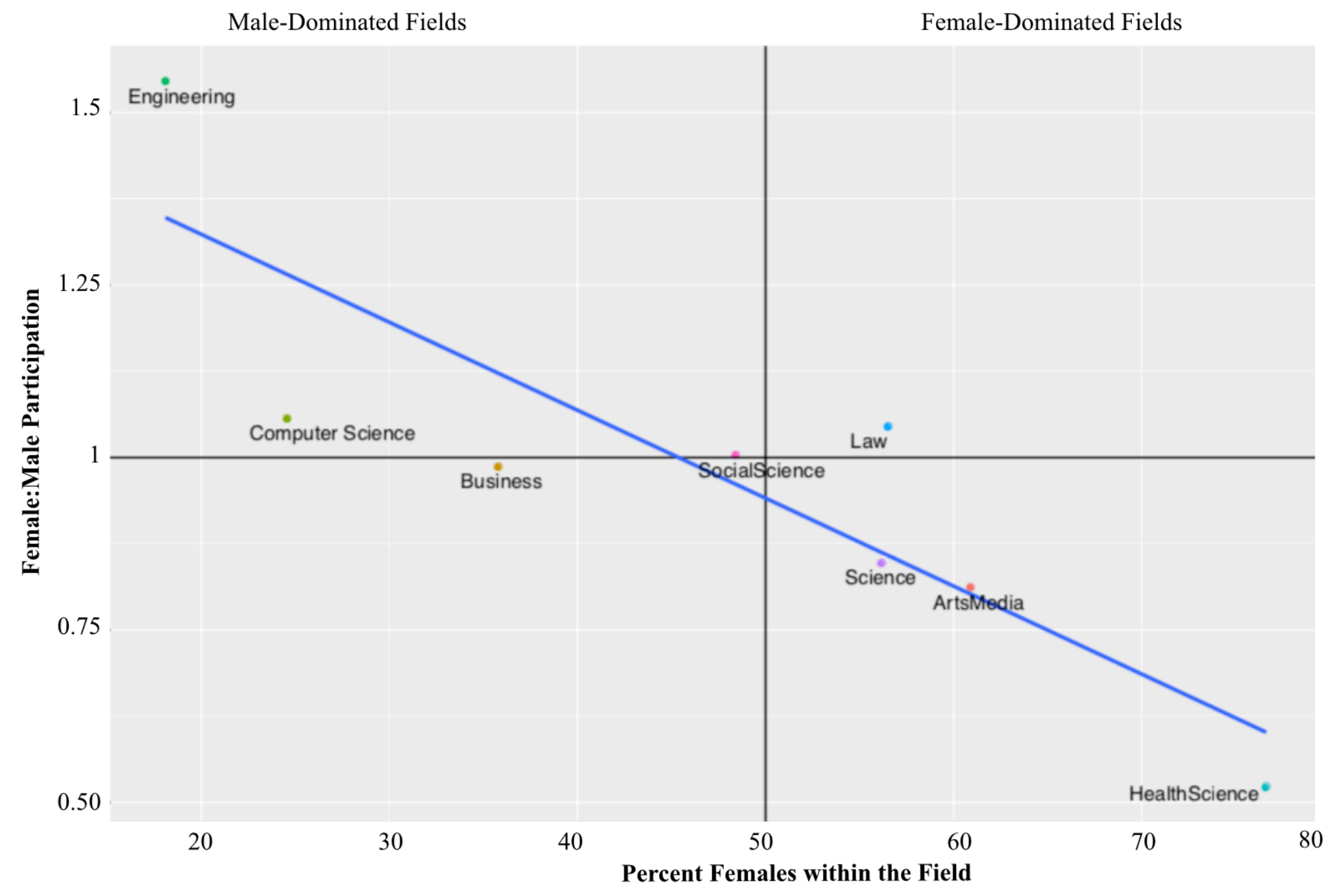

Figure 2 Females in Traditionally Male-Dominated Fields are More Willing to Participate than their Male Counterparts 


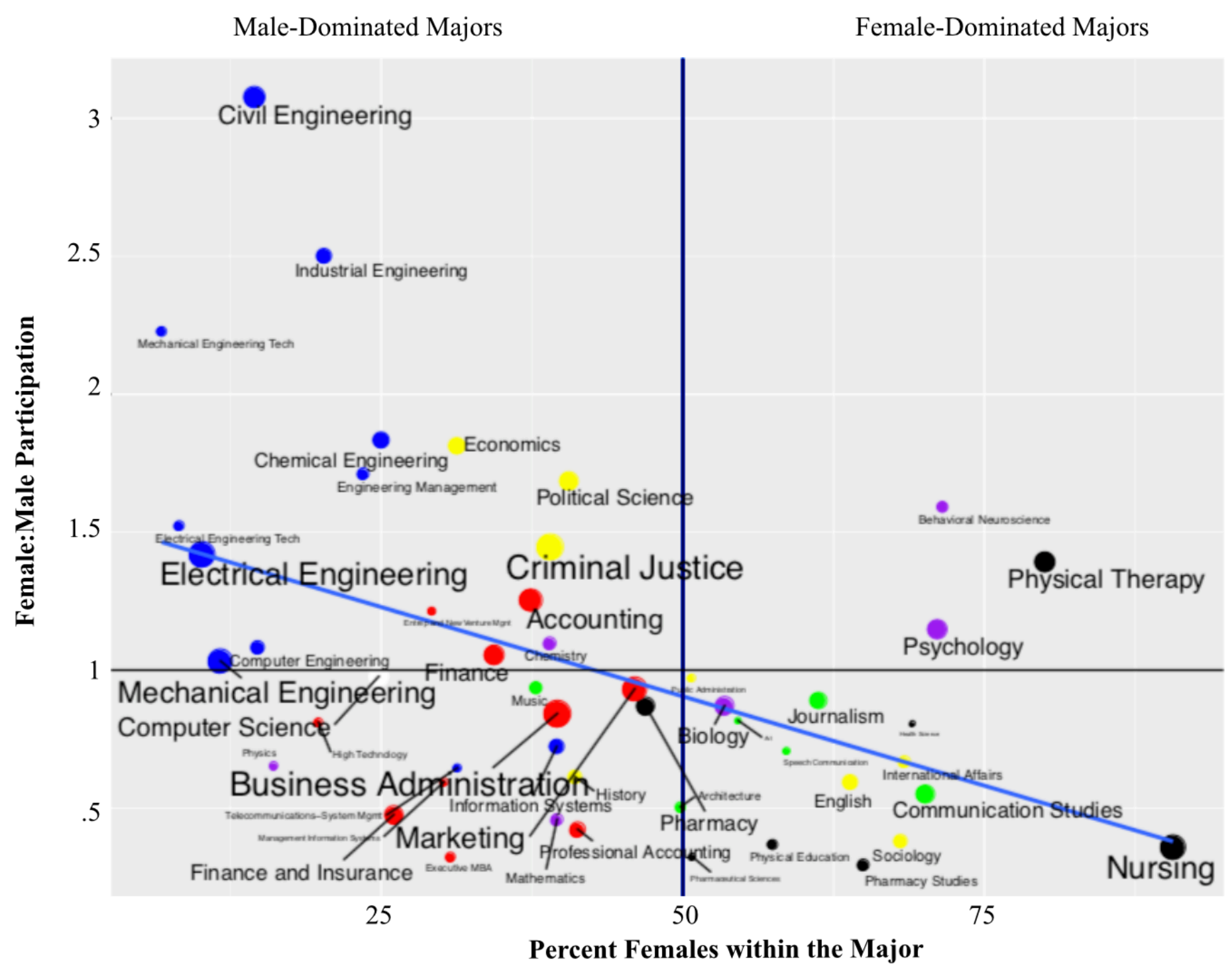

Figure 3 Females in Traditionally Male-Dominated Majors are More Willing to Participate than their Male Counterparts (relative numbers shown with bubble size) 


\section{Appendix}

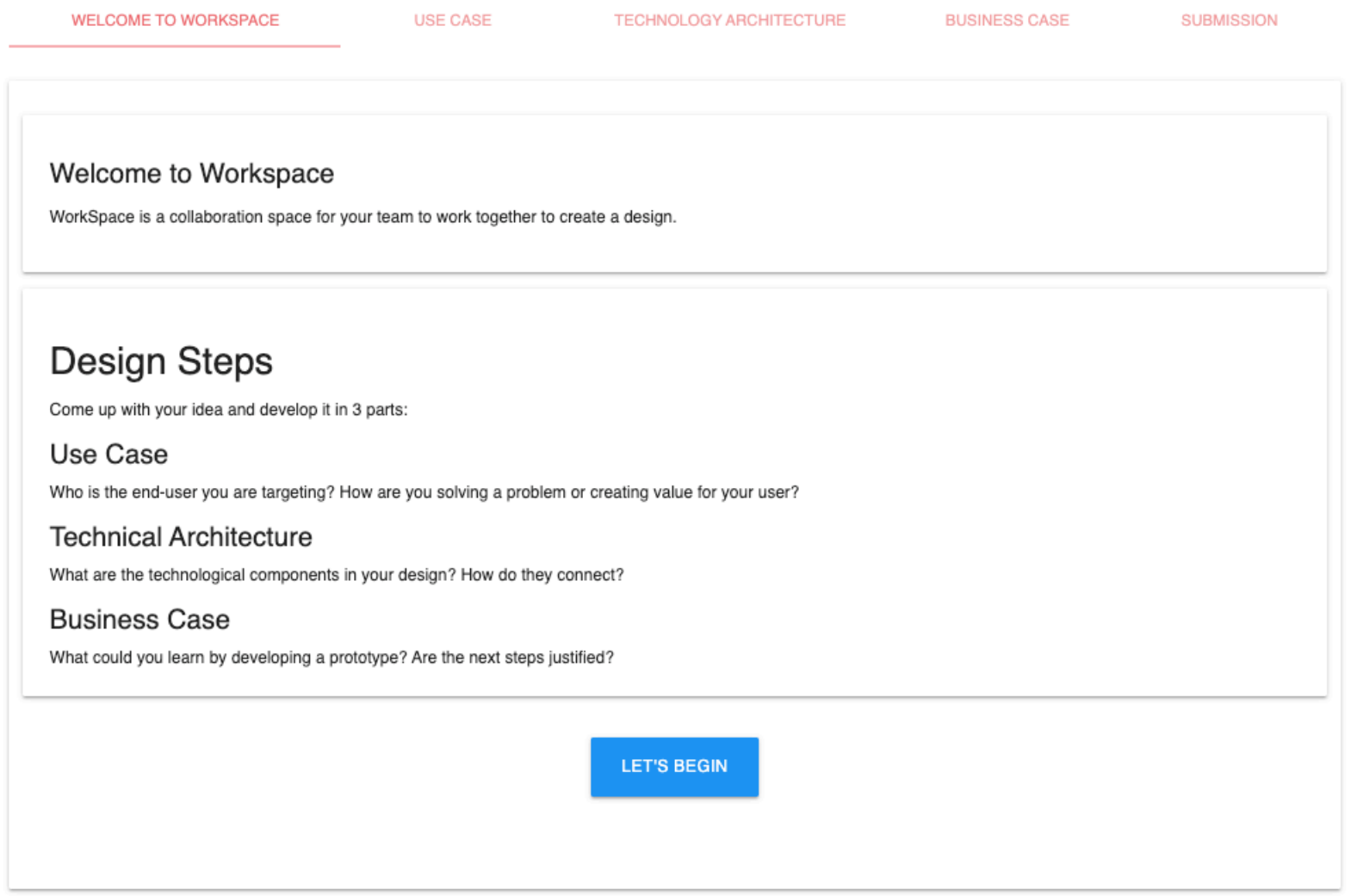

Fig. A1 Description of IoT Project Work: Design of Use Case, Technology Architecture, and Business Case for Prototype 
Technical Architecture

When innovating a new project, it is helpful to develop a clear hypothesis of the technical approach: the major building blocks in your design and how they fit together.

\section{Sensors, Actuators \& Devices}

Sensors measure data of most imaginable kinds, e.g., temperature, proximity, sound, buttons, switches, humidity, image, motion, acceleration, etc.

What kinds of sensors will you use? What do you need to measure?

Actuators control things and can make physical movements, e.g., motor, valve, door lock, robot arm, solenoid switch, etc.

Do you need actuators to physically control anything in your system?

Systems can also use other devices, e.g., smart phones, computers, tablets, smart speakers, etc..

Are there other devices in your system?

\section{Data, Algorithms \& Software}

It is also useful to describe your system in terms of data.

List and describe the data used or produced by your system? How are the data used?

Fig. A2 Sample Section of Technology Architecture Design Steps 


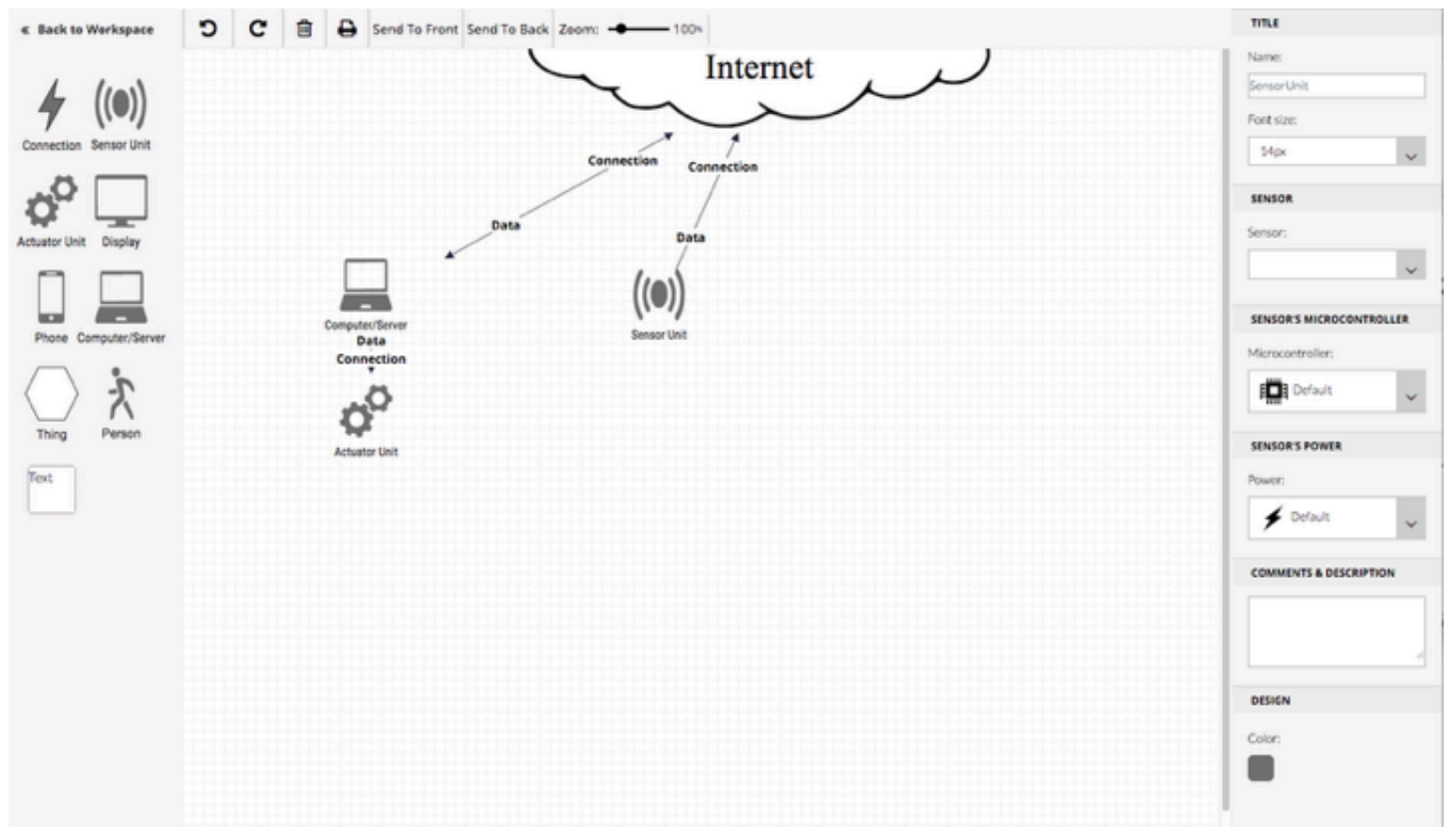

Fig. A3 Sample Technology Design Drag-and-Drop Design Tool 
Dear $<$ name $>$,

I'm reaching out to invite you to the university's new IoT Open Innovation platform, linking our students, alumni, staff, faculty and affiliated companies.

This is a two-sided collaborative platform to ideate and innovate "smart" Internet of Things (IoT) products and services - using hardware, software, networking, data and algorithms.

On one side of the platform, companies seek solutions to their IoT innovation challenges. On the other side, you will work within a team to solve IoT innovation problems of companies for cash and other benefits.

Click HERE to learn more and to sign up to the platform.

(This invitation is not transferable or to be forwarded.)

Fig. A4 Collaborative Condition Invitation 
Dear $<$ name $>$,

I'm reaching out to invite you to the university's new IoT Open Innovation platform, linking our students, alumni, staff, faculty and affiliated companies.

This is a two-sided competitive platform to ideate and innovate "smart" Internet of Things (IoT) products and services - using hardware, software, networking, data and algorithms.

On one side of the platform, companies seek solutions to their IoT innovation challenges. On the other side, you will compete with other participants to solve IoT innovation problems of companies for cash and other benefits.

Click HERE to learn more and to sign up to the platform.

(This invitation is not transferable or to be forwarded.)

Fig. A5 Competitive Condition Invitation 


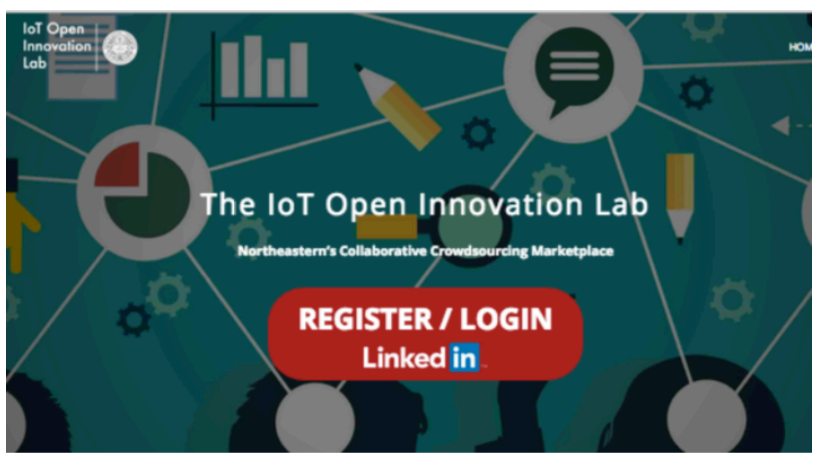

\section{Let's Collaborate and Create the Future}

Fig. A6 Collaborative Condition Landing Page 


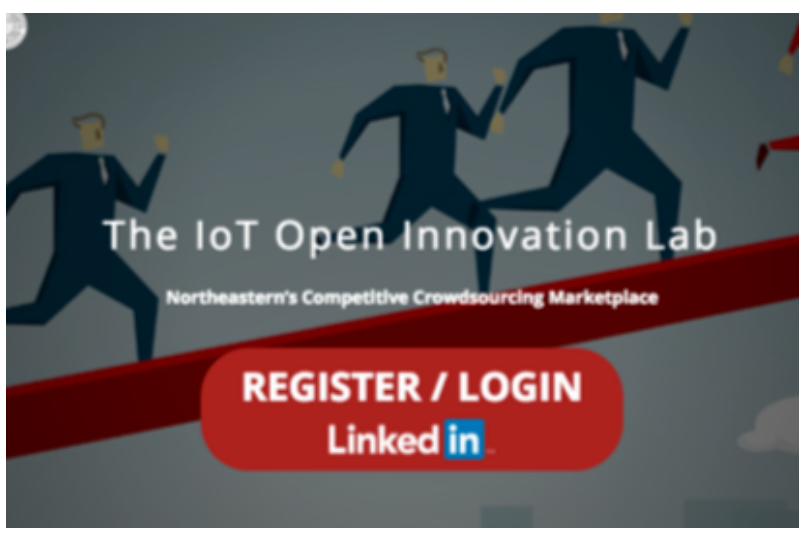

Fig. A7 Competitive Condition Landing Page 